\title{
PHYSIOLYTICS AT THE WORKPLACE: AFFORDANCES AND CONSTRAINTS OF WEARABLES USE FROM AN EMPLOYEE'S PERSPECTIVE
}

Tobias Mettler, Institut de hautes études en administration publique, University of Lausanne, Rue de la Mouline 28, 1022 Chavannes-près-Renens, Switzerland, e-mail: tobias.mettler@unil.ch Jochen Wulf, Institut für Wirtschaftsinformatik, University of St. Gallen, Müller-Friedberg-Strasse 8, 9000 St.Gallen, Switzerland, e-mail: jochen.wulf@unisg.ch

Citation. Mettler T \& Wulf J (forthcoming) Physiolytics at the workplace: affordances and constraints of wearables use from an employee's perspective. Information Systems Journal https://doi.org/ 10.1111/isj.12205

Abstract. Wearables paired with data analytics and machine learning algorithms which measure physiological (and other) parameters are slowly finding their way into our workplace. Several studies have reported positive effects from using such "physiolytics" devices and purported the notion that it may lead to significant workplace safety improvements or to increased awareness among employees concerning unhealthy work practices and other job-related health and wellbeing issues. At the same time, physiolytics may cause an over-dependency on technology and create new constraints on privacy, individuality, and personal freedom. While it is easy to understand why organizations are implementing physiolytics, it remains unclear what employees think about using wearables at their workplace. Using an affordance theory lens, we, therefore, explore the mental models of employees who are faced with the introduction of physiolytics as part of corporate wellness or security programs. We identify five distinct user types each of which characterizes a specific viewpoint on physiolytics at the workplace: the freedom-loving, the individualist, the cynical, the tech-independent, and the balancer. Our findings allow for better understanding the wider implications and possible user responses to the introduction of wearable technologies in occupational settings and address the need for opening up the "user black box" in IS use research.

Keywords. Affordance theory, physiolytics, Q-methodology, user research, wearables. 


\section{Introduction}

Wearable technologies ${ }^{1}$ have increasingly spread (Fox, 2013) and, to a certain extent, become mainstream for many of us (Dvorak, 2008). These body-worn minicomputers provide individual users with useful services and information while still being able to perform other tasks in parallel (Starner, 2014). For example, sensors seamlessly integrated into clothing, shoes, bracelets, phones, or watches support us in keeping track of physiological, behavioral, ecological, or otherwise parameters (Swan, 2013). Frequently, they nudge us towards better choices and decisions (Guo, 2015). This is particularly facilitated by wearables that Wilson (2013) refers to as "physiolytics", that is devices which link the measurement of body functions (e.g. heart rate, blood pressure, skin temperature, respiration) with data analytics and machine learning applications. In this way, unprecedented and more personalized advice can be offered to users that surpasses the possibilities of information portals or analytical tools that rely on traditional means of data collection.

Not only many tech-enthusiasts (i.e. body-hackers, life loggers, quantified-selfers, or selftrackers), but also organizations have spotted these advantages and incorporated physiolytics into their corporate wellness programs for the purpose of improving employees' health and well-being (Fingas, 2015; Olsen, 2014; Silverman, 2013). However, the use of physiolytics in an occupational setting is not unproblematic, as wearables create a massive data trail that businesses could harness and repurpose for other organizational goals, like job cuts or other drastic changes, which may be against the good of the workforce (Schall Jr, Sesek, \& Cavuoto, 2018). Not without good reason McAfee and Brynjolfsson (2012) therefore stated that individuals using wearables have become "walking data generators", giving organizations an opportunity to operate with many petabytes of extremely detailed and highly personal data. Because physiolytics implicates severe organizational and cultural changes, considerable insecurities and unpredictable employee behavior could emerge (Elie-Dit-Cosaque \& Straub, 2011). The introduction of physiolytics may even lead to resistance if a user's system appraisal is biased towards the personal risks that physiolytics entails (Lapointe \& Rivard, 2005). Therefore, managers of physiolytics initiatives in organizations, in order to achieve desired user responses, require a

\footnotetext{
${ }^{1}$ Note that in this article, we will use the terms wearable technology and wearable interchangeably.
} 
profound understanding of what determines user appraisal during system design (Anol Bhattacherjee, Davis, Connolly, \& Hikmet, 2017).

The current theory of IS appraisal particularly focuses on two aspects that influence an IS user's coping behavior: First, whether the user perceives a situation as an opportunity or a threat and, second whether or not the user is equipped with coping options (Beaudry \& Pinsonneault, 2005). While coping theory explains essential factors of a user's system appraisal, it alone does not sufficiently account for the complexities of user behavior (Fadel \& Brown, 2010). Understanding IS appraisal rather requires a deep knowledge of the relationship between the user, the technological artefact and the use context (Bødker, Gimpel, \& Hedman, 2014). In order to extend the current knowledge on IS appraisal in the context of physiolytics, we propose an affordance theoretical perspective that allows a fine-grained analysis (Leonardi, 2011; Volkoff \& Strong, 2013).

Because physiolytics exhibits a considerable disruptiveness, such an enriched understanding is particularly important (Elie-Dit-Cosaque \& Straub, 2011); some workers may perceive physiolytics as an opportunity, while others primarily see threats to their personal situation. Since conventional approaches to analyzing the appraisal of physiolytics systems prefer to differentiate users by deterministic variables, such as age, sex or marital status (Koo, 2017), an analysis of users' mental models may help to distinguish differences in perceptions of affordances and constraints that explain heterogeneous IS responses (Henfridsson \& Lindgren, 2010; Mettler, Sprenger, \& Winter, 2017). Taken together, adopting an affordance theoretic view may contribute to the current knowledge on IS appraisal because it enriches the current understanding of the conditions, under which users choose or modify IS responses (Anol Bhattacherjee et al., 2017). In this paper, we aim to contribute to the literature that we discuss above by addressing the following research questions. What do employees think about using physiolytics at the workplace? What affordances and constraints do they associate with physiolytics in their occupational environment? Do they share the same techno-enthusiasm as organizations wanting to implement such technologies?

As for now, two major research streams have tried to explain the complex relationship between users' perception and the introduction of new information technology (IT). The first stream, which follows a variance (Beaudry \& Pinsonneault, 2005; Legris, Ingham, \& Collerette, 2003) or 
variables-centered (Elbanna \& Linderoth, 2015) approach in understanding the use of IT, has yielded numerous and probably most recognized theories in explaining technology adoption (e.g. A. Bhattacherjee \& Premkumar, 2004; Davis, 1989; Venkatesh, Morris, Davis, \& Davis, 2003). Due to the deterministic nature of these types of studies, they have been frequently criticized either for their tendency to oversimplify the IT artifact, use, and user as relatively uniform, discrete, independent, and stable concepts that can be operationalized by a small number of contextual, behavioral and demographic variables (Bagozzi, 2007; Schwarz \& Chin, 2007), or for neglecting the role of rich and convoluted user experiences in deciphering why a certain type of user would use an emerging (or controversial) technology and others not (Breward, Hassanein, \& Head, 2017; X. Zhang \& Chignell, 2001).

Partially as a response to this criticism, a second stream of research has examined the introduction and use of technology from a process perspective (Beaudry \& Pinsonneault, 2005). Different from the previously mentioned research, these studies have focused on explaining how users make sense of technology-induced change (Davidson \& Pai, 2004; Leonardi, 2011; Volkoff \& Strong, 2013), how shared perceptions about technology come into being (Elbanna \& Linderoth, 2015; Mettler et al., 2017), and how these ultimately affect use and infusion of technology (Al-Natour \& Benbasat, 2009). Given that different beliefs, attitudes, aspirations, and interpretations of technology may result in divergent, sometimes unsatisfactory or unintended use behavior (Henfridsson \& Lindgren, 2010; Mettler, 2018; Vitharana, Zahedi, \& Jain, 2016), the search for explaining mental models, understood as organized cognitive structures that individuals form to make sense of the world around them (Rouse \& Morris, 1986), has played an important role in this stream of research ever since (Donald A Norman, 2014).

Following this line of thought, the starting point of this paper is that current studies on the use of wearables, and of physiolytics in particular, do not sufficiently accommodate the diversity and parallelism in affordances and constraints perceived by users that eventually may arise from its introduction in an occupational setting. Most studies emanate from the lens of voluntary use (e.g. in a leisure context) and continue to treat users as "black box". This is unfortunate given that having a profound knowledge of mental models and appreciating the users' different standpoints may help to explain and mitigate possible causes of resistance and avoid failure of implementation (Juhani Iivari \& Iivari, 2011; J. Iivari, Isomäki, \& Pekkola, 2010). By opening up 
the "user black box", this paper seeks to increase our understanding on the role of affordances and constraints in a user's sensemaking process. The mental models we identify and present in the remainder of this paper are, in a way, the user's result of a "meaning making" process (Bruner, 1990), and intended to serve as an aid for better comprehending the complex relations between user perception and the introduction and use of physiolytics at the workplace.

\section{$2 \quad$ Background}

As mentioned above, prior work on physiolytics has studied first and foremost its introduction and use for leisure or home settings (e.g., Canhoto \& Arp, 2017; Carlsson \& Rooth, 2007; Li, Wu, Gao, \& Shi, 2016; Marakhimov \& Joo, 2017; Wiegard \& Breitner, 2017; M. Zhang, Luo, Nie, \& Zhang, 2017) and have therefore not specifically looked into occupational use contexts which are significantly different from typical consumer choice situations. On the one hand, since organizations bear a great part of the investment costs, considerable pressure could be imposed on employees to use physiolytics at the job and to disclose very personal information although there are legal protections against privacy violations. On the other hand, the positive impact of physiolytics on personal health and well-being is still contested in research (Calvo \& Peters, 2013; Shull, Jirattigalachote, Hunt, Cutkosky, \& Delp, 2014).

To date, the majority of papers describing application scenarios in occupational settings mostly concentrate on technical and operational aspects, as we detail next. The few studies we found that take an IS perspective on physiolytics at the workplace mostly stemmed from the variance or variables-centered stream of research and applied descriptive statistics (Schall Jr et al., 2018), regression models (Choi, Hwang, \& Lee, 2017; Yassaee \& Mettler, 2017), or qualitative analysis (Greenfield et al., 2016) for studying the phenomenon without distinguishing different user perceptions. These papers leave behind particular worldviews and realities of users, which could have served as basis for comparison

\subsection{Application scenarios of physiolytics at the workplace}

As shown in Table 1, various application scenarios, prototypes, and instantiated system properties are prominently discussed in the literature. Today, a particularly eminent application scenario of physiolytics is the detection of work-related stress because it was evidenced that it is responsible for major health issues, particularly for those employees in digital workplaces 
(Köffer, 2015). For instance, Han et al. (2017) discuss a solution design, which links an electrocardiogram with a respiration sensor, that facilitates a reliable prediction of stress levels. In communicating this information to workers, according to the authors, an appropriate work condition can be maintained.

Reducing sedentary behavior at the workplace is another frequent application scenario. For example, Pina, Ramirez, and Griswold (2012) propose a relatively simple physiolytics system that consists of a step counter, a server-based inactivity recognizer, and an activity notification service that supports workers in avoiding excessive sitting.

In the same vein, other scholars (Chung \& Danis, 2016; Glance, Ooi, Berman, Glance, \& Barrett, 2016; Gorm \& Shklovski, 2016; Vyas et al., 2015) have reported on employer-sponsored health programs that include physical activity tracking in order to generally reduce physical inactivity. Physiolytics solutions in these programs, apart from pedometers, additionally include usercentered applications for the definition of goals, the reporting of goal achievements, and for performance benchmarking. Social design features including badges, activity sharing, and teamlevel competitions, frequently extend these user-centered applications for the purpose of continued engagement and habit formation (Alahäivälä \& Oinas-Kukkonen, 2016).

The opposite case, that is fatigue from excessive physical or mental work, represents another significant risk factor for an employee's health. Based on the case of vehicular drivers in logistics and public transportation, Bundele and Banerjee (2009) discuss a sophisticated physiolytics solution that uses skin conductance, oximetry pulse sensors, and neural-network-based classifier algorithms for accurately detecting driving fatigue. Following them, complementing such a fatigue detection with in-built warning systems in vehicles or other working equipment may significantly mitigate the risk of accidents.

Lastly, health issues may also emanate from incorrectly carrying out heavy labor (e.g. construction or assembly line work). For this application scenario, different solutions aiming at monitoring and improving occupational ergonomics are discussed (Cheng, Migliaccio, Teizer, \& Gatti, 2013; Peppoloni, Filippeschi, Ruffaldi, \& Avizzano, 2016; Valero, Sivanathan, Bosché, \& Abdel-Wahab, 2016). In identifying risk factors, like bad work posture or poorly coordinated movement, many of the presented solutions rely on sensors for inertial measurement, location sensing, and motion detection algorithms together with instant feedback mechanisms. 
In sum, our literature review demonstrates that various technological properties are currently built into physiolytics solutions in order to serve different application scenarios. However, this only partially helps us to comprehend the users' viewpoint and cognitive structures they form to make sense of this technology. Accordingly, we will now turn to a description of action possibilities and constraints that may emerge when actors engage with solutions similar to the ones we presented here.

Table. 1. Literature review on physiolytics scenarios, prototypes, and system properties

\begin{tabular}{|c|c|c|}
\hline Health risk & Exemplary prototypes [outlet] & Exemplary system properties \\
\hline Stress & $\begin{array}{l}\text { - Solution for the purpose of detecting work-related } \\
\text { stress of office workers by means of a wearable } \\
\text { device (Han et al., 2017) [Computers in Industry] }\end{array}$ & $\begin{array}{l}\text { - Electrocardiogram and respiration } \\
\text { sensor } \\
\text { - Random Forest and Support Vector } \\
\text { Machine classification }\end{array}$ \\
\hline $\begin{array}{l}\text { Sedentary } \\
\text { behavior }\end{array}$ & $\begin{array}{l}\text { - Behavior-based intervention system to reduce } \\
\text { sedentary behavior at the workplace (Pina et al., } \\
\text { 2012) [International Conference on Pervasive } \\
\text { Computing Technologies for Healthcare] }\end{array}$ & $\begin{array}{l}\text { - Wearable (step counter) } \\
\text { - Inactivity recognizer } \\
\text { - Activity instruction notification }\end{array}$ \\
\hline $\begin{array}{l}\text { Physical } \\
\text { inactivity }\end{array}$ & $\begin{array}{l}\text { - Fitbit application in company wellness program } \\
\text { (Chung \& Danis, 2016) [International Conference } \\
\text { on Pervasive Computing Technologies for } \\
\text { Healthcare] } \\
\text { - Digital activity tracker-based workplace (Glance et } \\
\text { al., 2016) [CHI Conference on Human Factors in } \\
\text { Computing Systems.] } \\
\text { - Physical activity tracking in an employer- } \\
\text { sponsored health-program (Vyas et al., 2015) } \\
\text { [ACM Conference Extended Abstracts on Human } \\
\text { Factors in Computing Systems] } \\
\text { - Step-counting campaign in the workplace (Gorm } \\
\text { \& Shklovski, 2016) [ACM Conference on } \\
\text { Computer-Supported Cooperative Work \& Social } \\
\text { Computing] }\end{array}$ & $\begin{array}{l}\text { - Pedometer } \\
\text { - Reports of step count totals on } \\
\text { individual, third party, and team } \\
\text { level } \\
\text { - Step goal customization interface } \\
\text { - Benchmark visualizations } \\
\text { - Walking recommendations } \\
\text { - Goal achievement reports } \\
\text { - Online reminders } \\
\text { - Badges, prices, leaderboards } \\
\text { - Activity visualization on map } \\
\text { (activity sharing) }\end{array}$ \\
\hline Fatigue & $\begin{array}{l}\text { - Solution for detecting fatigue of vehicular drivers } \\
\text { (Bundele \& Banerjee, 2009) [International } \\
\text { Conference on Information Integration and web- } \\
\text { based applications \& services] }\end{array}$ & $\begin{array}{l}\text { - Skin conductance and oximetry } \\
\text { pulse sensors } \\
\text { - Neural-network-based classifier }\end{array}$ \\
\hline Heavy labor & $\begin{array}{l}\text { - Solution for discovering unsafe postures of } \\
\text { construction workers (Valero et al., 2016) [Applied } \\
\text { Ergonomics] }\end{array}$ & $\begin{array}{l}\text { - Inertial measurement units } \\
\text { connected to body area network } \\
\text { - Real-time worker location sensing }\end{array}$ \\
\hline
\end{tabular}




\begin{tabular}{lll}
\hline Health risk & Exemplary prototypes [outlet] & Exemplary system properties \\
\hline - Solution for monitoring ergonomics in & - Physical motion detection \\
& construction industry (Cheng et al., 2013) [Journal & algorithms \\
& of Computing in Civil Engineering] & - Instant feedback (beep or vibration) \\
- Solution for the assessment of biomechanical load & - Data and performance visualization \\
& in repetitive efforts of supermarket cashiers \\
& (Peppoloni et al., 2016) [International Journal of \\
& Industrial Ergonomics]
\end{tabular}

\subsection{Affordances and constraints of physiolytics at the workplace}

Originating amongst others from the seminal work of Gibson (1979), affordance theory has been popularized for analyzing technology use and for explaining the interdependency of human agency and the materiality of technology without being either technologically or socially deterministic (Leonardi, 2011; Pozzi, Pigni, \& Vitari, 2014; Seidel, Recker, \& vom Brocke, 2013). To date, several different stances and interpretations of how to theoretically understand affordances exist (Lanamäki et al, 2016). In this paper, we follow the notion proposed by Faraj and Azad (2012) and Volkoff and Strong (2013) and comprehend affordances as potentials for different actions and behaviors arising from the relationship between technology and a goaloriented individual who seeks to achieve an immediate concrete outcome. According to this understanding, affordances are viewed as generative mechanisms that need people to be uncovered, but which can exist regardless of a person (Bygstad, Munkvold, \& Volkoff, 2016). This is possible because certain individuals may share the same mental models and thus perceive the technological potentials likewise (Majchrzak \& Markus, 2012). Similar to an affordance, individuals may also perceive a constraint that a technology imposes to them and that confines their ability to achieve the desired outcome (Leonardi, 2011; Majchrzak \& Markus, 2012).

In this sense, affordance theory deals with potentials and not with actual uses of technology (Markus \& Silver, 2008). Prior to interacting with a technology, people actively construct perceptual affordances and constraints by reconciling their own goals with the materiality of this technology (Leonardi, 2011). The perception of affordances is a requirement for affordance actualization and represents an important antecedent of the intention to use a certain technology (Junglas, Goel, Abraham, \& Ives, 2013; D.A. Norman, 1990). In short, the analysis of affordances and constraints, as relational concepts, helps to explain patterns of similarity and differences in technology use across individuals (Majchrzak \& Markus, 2012). 
Our literature analysis reveals that employees may perceive several affordances or constraints of physiolytics. We begin with discussing affordances (AFF), which we summarize in Table 2, and discuss constraints (CON) thereafter.

Table. 2. Literature review on physiolytics affordances

\begin{tabular}{|c|c|c|}
\hline Affordance (AFF) & Description & References \\
\hline $\begin{array}{l}\text { Action potential to } \\
\text { improve workplace } \\
\text { security }\left(\mathrm{AFF}_{1}\right)\end{array}$ & $\begin{array}{l}\text { - Enhancing the ability to detect safety } \\
\text { violations or hazardous situations at work } \\
\text { - Improving response to harmful or } \\
\text { potentially dangerous job-related events }\end{array}$ & $\begin{array}{l}\text { (Choi et al., 2017; Gao, Li, \& } \\
\text { Luo, 2015; Karahoca et al., } \\
\text { 2017; Schall Jr et al., 2018) }\end{array}$ \\
\hline $\begin{array}{l}\text { Action potential to better } \\
\text { adapt to the work } \\
\text { environment } \\
\left(\mathrm{AFF}_{2}\right)\end{array}$ & $\begin{array}{l}\text { - Increasing the ability to record task-person } \\
\text { misfits } \\
\text { - Rectifying one's work environment to one's } \\
\text { physical characteristics }\end{array}$ & $\begin{array}{l}\text { (Choi et al., 2017; Koskimäki, } \\
\text { Huikari, Siirtola, Laurinen, \& } \\
\text { Röning, 2009; Mura, Dini, \& } \\
\text { Failli, 2016) }\end{array}$ \\
\hline $\begin{array}{l}\text { Action potential to } \\
\text { improve awareness and } \\
\text { cognition }\left(\mathrm{AFF}_{3}\right)\end{array}$ & $\begin{array}{l}\text { - Improving awareness and reflection on job- } \\
\text { related issues with health and well-being } \\
\text { - Enhancing the ability to counteract or } \\
\text { withstand unhealthy work practices }\end{array}$ & $\begin{array}{l}\text { (Greenfield et al., 2016; Li et al., } \\
\text { 2016; Puri et al., 2017; Wiegard } \\
\text { \& Breitner, 2017; Yassaee \& } \\
\text { Mettler, 2017) }\end{array}$ \\
\hline $\begin{array}{l}\text { Action potential to signal } \\
\text { adherence to group } \\
\text { norms and values }\left(\mathrm{AFF}_{4}\right)\end{array}$ & $\begin{array}{l}\text { - Increasing social and professional } \\
\text { recognition from conformant behavior } \\
\text { - Enhancing the ability to adhere to group } \\
\text { norms and organizational inclusion }\end{array}$ & $\begin{array}{l}\text { (Canhoto \& Arp, 2017; Choi et } \\
\text { al., 2017; Karahoca et al., 2017; } \\
\text { Yassaee \& Mettler, 2017; M. } \\
\text { Zhang et al., 2017) }\end{array}$ \\
\hline
\end{tabular}

A key affordance of physiolytics, in our context of study, is establishing workplace security. It enables employees to avoid an unsafe execution of work activities by, for example, detecting bad posture or fatigue (Schall Jr et al., 2018). Based on the continuous tracking of physiological parameters (e.g. blood pressure, heart rate variability) and the integration and analysis of other data sources, physiolytics may also support employees in identifying injuries and diseases at early stages (Gao et al., 2015; Karahoca et al., 2017) or in effectively reacting to abnormal hazardous events and thus reduce the risk of accidents (Choi et al., 2017).

Again Choi et al. (2017) highlight the complementary affordance of enabling employees to spot excessive workloads beyond one's physical capabilities. This, in turn, allows the worker (or supervisor) to optimize the workload accordingly. Studies of wearable use in industrial settings suggest that data obtained from physiolytics devices may contribute to better task allocation and ultimately improve health conditions of workers in industrial assembly lines (Koskimäki et al., 2009) or machine maintenance (Mura et al., 2016). In this sense, it may afford the opportunity 
to efficiently adapt one's work environment to one's physical characteristics or, at least, record problems with task-person-fit.

Physiolytics also offers the potential to improve awareness and cognition about health issues at work (Li et al., 2016). As discussed before, solutions exist that support workers in discovering and counteracting excessive sedentary behavior or lack of physical activity at the workplace (Greenfield et al., 2016; Puri et al., 2017; Wiegard \& Breitner, 2017). They may afford employees a new, unprecedented way of changing unhealthy work practices by actively supporting them with personalized instructions for health improvement (Yassaee \& Mettler, 2017).

Finally, many physiolytics solutions provide the possibility for signaling adherence to group norms and values. Such applications enable employees to share personal achievements with colleagues and managers. They are therefore perceived by some authors to be instruments for gaining social and professional reputation at work (Canhoto \& Arp, 2017; Karahoca et al., 2017; Yassaee \& Mettler, 2017). Accordingly, an open and transparent communication of individual or group health-related indicators could be viewed as an extrinsic motivator for changing unhealthy work practices and becoming healthier (Choi et al., 2017; M. Zhang et al., 2017).

Apart from affordances, the reviewed literature also suggests various constraints that employees may perceive, which we summarize in Table 3 and detail next.

Table. 3. Literature review on physiolytics constraints

\begin{tabular}{lll}
\hline Constraint (CON) & Description & References \\
\hline Constraint on privacy & - Losing sovereignty of personal and sensitive & (Greenfield et al., 2016; Li et al., \\
$\left(\mathrm{CON}_{1}\right)$ & physiological data to third parties & 2016; Marakhimov \& Joo, 2017; \\
& - Limiting the ability to actively control & Schall Jr et al., 2018; Yassaee \& \\
& information disclosure & Mettler, 2017; M. Zhang et al., \\
& & 2017) \\
\hline Constraint on personal & - Reducing job-related autonomy & (Choi et al., 2017; Greenfield et \\
freedom $\left(\mathrm{CON}_{2}\right)$ & - Diminishing the possibility of pursuing self- & al., 2016) \\
& contained and innovative decisions at work & \\
\hline Constraint on technology & - Diminishing the ability to make considered & (Duus, Cooray, \& Page, 2017; \\
independence $\left(\mathrm{CON}_{3}\right)$ & decisions without technology & Hofmann, 2013) \\
& - Losing responsibility and self-reliance at & \\
& work & \\
\hline
\end{tabular}




\begin{tabular}{lll}
\hline Constraint (CON) & Description & References \\
\hline Constraint on & - Reducing individuality by submerging the & (Choi et al., 2017; Greenfield et \\
individuality $\left(\mathrm{CON}_{4}\right)$ & self within the group & al., 2016) \\
& - Jeopardizing procedural fairness and & \\
& situational adequacy of job performance \\
& reviews & \\
\hline
\end{tabular}

As many scholars have pointed out (Li et al., 2016; Marakhimov \& Joo, 2017; M. Zhang et al., 2017), physiolytics comes with a severe privacy risk that sensitive or private data is accessed by third parties without an employee's consent. There is a constant peril that employers repurpose physiolytics data against the interests of their employees for motives other than employee's health and well-being (Schall Jr et al., 2018; Yassaee \& Mettler, 2017). As Greenfield et al. (2016) exemplarily illustrate in their study, a truck driver's physiolytics data may be misused to infer implications on driving behavior and performance.

Another constraint frequently discussed in the literature is the deprivation of personal freedom. Since employers may gain broad access to employee activity data, this could limit an employee's self-determination in planning, structuring, and performing work activities. This, in turn, may lead to a decrease of motivation and degrade creativity at the workplace. Again, the truck driver's case described by Greenfield et al. (2016) discusses the possibility that physiolytics devices may possibly restrain the employee in his or her free choice when it comes to the selection of a suitable location and time for making a break. Similarly, Choi et al. (2017), in a survey of construction workers, show that the use of physiolytics devices for collecting worker activity patterns for the purpose of increasing efficiency ultimately leaves construction workers with less personal freedom to organize their job.

The extensive use of physiolytics devices at work may potentially lead to an overreliance on technology (Duus et al., 2017). Consequently, employees may become helpless in case of technology outages and other operational failures. In this sense, the introduction and use of physiolytics may constrain the employee in his or her technology independence and inadvertently result in conflicts or unwarranted transfer of decision responsibility (Hofmann, 2013). For example, a physiolytics user may, against better knowledge, rely on the physiolytics device's diagnosis instead of trusting his or her own sense of well-being. 
Since physiolytics data assumedly provides objective evidence of an employee's performance, it may last but not least also lead to possible coercion, unfair decisions, or even discrimination of a certain group of workers. In case physiolytics is applied to deterministically derive job-related implications, it may severely constrain personal individuality and create additional pressure at work, particularly among those who are reluctant to share physiolytics data with their co-workers (Choi et al., 2017).

\section{Research method}

Different cognitive mapping techniques can and have been used in attempts to investigate how people think about and make sense of the phenomena in their world. To explore the mental models that employees have developed regarding the use of physiolytics at the workplace, we have chosen to apply a mixed-method approach called Q-methodology (W. Stephenson, 1986), as it offers a rigorous and systematic way for capturing human subjectivity. Although it has been frequently used in other fields, such as policy research (Armatas, Venn, \& Watson, 2014; Steven R Brown, 1980) or health services research (R. Baker, Wildman, Mason, \& Donaldson, 2014; Cross, 2005; Stenner, Cooper, \& Skevington, 2003), it has been rather uncommon in IS research (Thomas \& Watson, 2002). Nonetheless, some studies have been published in prestigious IS journals over the years. For instance, Tractinsky and Jarvenpaa (1995) applied Q-methodology for studying differences in the decision-making of project managers regarding the IT distribution in enterprises. Storey, Straub, Stewart, and Welke (2000) used Q-methodology as an alternative approach for segmenting the e-commerce industry based on personal opinions of major ecommerce providers. Klaus, Wingreen, and Blanton (2010) performed a study involving Qmethodology for investigating user resistance in enterprise system implementation. Similarly, Mettler et al. (2017) used Q-methodology for studying different attitudes towards the adoption of service robots.

Q-methodology shares many similarities with other cognitive mapping techniques, such as the RepGrid technique (Tan \& Hunter, 2002), multidimensional scaling (Ferguson, Kerrin, \& Patterson, 1997), or cognitive causal mapping (Eden, 2004; Ghobadi \& Mathiassen, 2015). All mentioned techniques typically operate on small sample sizes (Dziopa \& Ahern, 2011), within a clearly delimited area of interest or phenomenon, and involve some kind of operationalization 
of subjective statements from individuals (e.g. using rating scales, or card sorting exercises), and a subsequent interpretation and/or visualization of these statements and relationships in a meaningful way (e.g. using similarity ratings, concept maps, cluster or factor analyses). However, there are many nuances in terms of how these techniques set limits regarding (a) the elicitation method, (b) structural representation, and (c) representation of emergence for capturing mental models (DeChurch \& Mesmer-Magnus, 2010).

As we will detail below, Q-methodology attaches particular importance to the sampling of subjective statements and less on a representative sampling of individuals as is often emphasized by other techniques, as well as to the emergence of mental models by describing the degree of consensus or disagreement at focal level of analysis. Different from comparative causal mapping (Ghobadi \& Mathiassen, 2015; Laukkanen \& Eriksson, 2013), Q-methodology does not detail the structure or causality that led to a mental model nor how the identified worldviews are related to each other. It also differs from RepGrid, which often combines qualitative content analysis with a quantitative cluster analysis, as its analytical procedure is usually limited to the interpretation of numeric factor scores (without any visual output such as a concept map). Nevertheless, a particular strength of Q-methodology (compared to purely interpretive approaches) is to construe from the quantitative analysis some generalizations about the respondents' opinions, which are similar to those obtained from positivist research, however, without neglecting the fact that these findings are socially constructed and based on the subjectivity of respondents and researchers (Dziopa \& Ahern, 2011). Combined with other methods, such as discourse analysis, it can build a solid foundation for more quantitative confirmatory studies (Zabala, 2014). Moreover, Q-methodology often uncovers unusual or counterintuitive patterns that are unrelated to observable demographic characteristics and hence may not be detected with typical survey-based studies (Zabala \& Pascual, 2016). This said, we have followed five methodological steps, which we detail in the following subsections and summarize in Table 4, in order to examine similarities and differences in perceiving affordances and constraints of physiolytics at the workplace. 
Table. 4. Methodological steps followed in this Q-methodology study

\begin{tabular}{|c|c|c|}
\hline Methodological steps & Definition & Implementation \\
\hline a & $\begin{array}{l}\text { Initial collection of statements, each } \\
\text { making a different, but nonetheless } \\
\text { recognizable, assertion about the } \\
\text { topic of interest. }\end{array}$ & $\begin{array}{l}\text { We started our inquiry by searching for } \\
\text { journal publications, news articles, and } \\
\text { websites, which described general } \\
\text { affordances and constraints of wearables } \\
\text { and of physiolytics in particular. We } \\
\text { formulated a list of } 45 \text { statements based on } \\
\text { the identified sources. }\end{array}$ \\
\hline Ste & $\begin{array}{l}\text { Development of a representative set } \\
\text { of statements that are drawn from the } \\
\text { concourse. Most often statements are } \\
\text { transcribed onto cards for facilitating } \\
\text { the later Q-sorting. }\end{array}$ & $\begin{array}{l}\text { For validation and refinement of the initial } \\
\text { concourse, we conducted } 12 \text { open-ended } \\
\text { interviews with domain experts, which we } \\
\text { first recruited by telephone and second by } \\
\text { applying the "snowballing" technique, as } \\
\text { described by Myers and Newman ( } 2007) \text {, to } \\
\text { extend the sample further. Guided by the } \\
\text { interview results, we reduced the initial } \\
\text { concourse to } 32 \text { statements. }\end{array}$ \\
\hline Step 3: Q-S & $\begin{array}{l}\text { Selection of study participants and } \\
\text { letting them compare and rank the Q- } \\
\text { sample statements concerning how } \\
\text { much they agree or disagree based } \\
\text { on determined sorting instructions. }\end{array}$ & $\begin{array}{l}\text { To obtain subjective viewpoints and } \\
\text { perceptions of employees affected by the } \\
\text { introduction of physiolytics in the short or } \\
\text { medium term, we recruited by e-mail and } \\
\text { advertisement on our institutional website } \\
20 \text { respondents. Each person was given a } \\
\text { link to the Q-sortware platform for } \\
\text { performing the q-sort procedure online. }\end{array}$ \\
\hline $\begin{array}{l}\text { Step 4: Quantitative } \\
\text { data analysis }\end{array}$ & $\begin{array}{l}\text { Performing a factor analysis and } \\
\text { analyzing the correlation coefficients } \\
\text { representing the degree of } \\
\text { concordance between an individual } \\
\text { Q-sort and a generalized factor. }\end{array}$ & $\begin{array}{l}\text { The gathered data was analyzed using the } \\
\text { Principal Component Analysis (PCA) with } \\
\text { Varimax rotation provided by the STATA } \\
\text { software package. Further visual analyses } \\
\text { were conducted using Microsoft Excel. }\end{array}$ \\
\hline
\end{tabular}




\begin{tabular}{lll}
\hline Methodological steps & Definition & Implementation \\
\hline Step 5: Interpretation & Interpretation of factor scores and We interpret the factors by looking at the \\
of the quantitative & variance of statements across all statement scores of each identified user \\
findings & identified factors. & group and the distances of specific \\
& & statement scores to neighboring factors' \\
& scores. Each interpreted mental model is \\
& summarized in form of a narrative
\end{tabular}

But before we turn to a detailed description of our research design, it is important to note that Q-methodology also presents a number of limitations, which we think that IS researchers interested in applying this method should be aware of. To start with, Q-methodology involves multiple data collection rounds and matrix algebra operations (S. R. Brown, 1993); some steps are based on informed/analytical, others on subjective/judgmental decision-making by the researcher. Although there are some statistical guidelines or rules-of-thumb, sometimes decisions must be taken from a theoretical or pragmatic point of view. For instance, in step 1 (concourse) the researcher may derive statements based purely on desk research or may also include primary data which he/she obtained by preceding focus group discussions, expert interviews, or other field research methods. In step 2 (Q-sample), the selection of the number and content of cards is equally discretionary. This decision may be based on a theoretical reasoning (but must not) or could likewise be guided by practical issues, as for example, deliberately reducing the number of statements for simplifying and speeding up the sorting process to avoid that participants respond in a "mechanical" way like it is commonly found in survey-based studies (Corr, 2001). In step 3 (Q-sorting), a decision must be taken with respect to rating scales and distribution (fixed vs. undetermined) underlying the sorting exercise. Finally, in step 4 (quantitative analysis), there is a choice to make regarding the factor extraction (e.g. PCA vs. EFA) and rotation method (e.g. orthogonal vs. oblique vs. unrotated solution). All these decisions influence, to some extent, the range, informative value, and interpretability of possible results. Therefore, the replicability and reliability of Q-methodology studies have frequently been disputed. For instance, Cross (2005) noted that when repeated on the same persons, Q-methodology does not necessarily yield the same results. Although some researchers affirm that a Q-sorting can be replicated with 
$85 \%$ consistency up to a year later (Steven R Brown, 1980), there is disagreement in the literature which has led to claims and suggestions to fix this issue (Zabala \& Pascual, 2016). Some researchers also criticized the neglect of path dependency in decision-making (Rachel Baker, Thompson, \& Mannion, 2006), as it assumed that the placing of a card in the continuum of possible responses is not affected by previous or later placements. Again, there is a dissent whether this issue significantly alters the outcome of a study. However, according to Rachel Baker et al. (2006), this issue can be countered by an adequately sized Q-sample and the raising of the required probability from 0.05 to 0.01 for significance in factor loadings-as was applied in this study (cf. Table A2).

Besides these rather procedural issues, Q-methodology also faces some problems with respect to the interpretation of results and its acceptance among positivist researchers. Following Ramlo and Newman (2011), the interpretation of Q-sorts is an extensive qualitative process. In order to take the analysis beyond the most basic descriptive and counting exercise-in addition to being able to perform the quantitative analysis-the researcher needs to develop further analytical skills in moving towards hypotheses or propositions about how to exploit the data in a meaningful way. In our case, the combined use of numerical, graphical, and content analysis was instrumental in the process of making sense of the obtained data. Particularly, different visualizations about the placement of statements (cf. Table A3 and A4) facilitated an easier interpretation of the factor scores. However, because findings are interpretative in nature, Qmethodology studies are frequently misunderstood. First, Q-methodology has no interest in estimating population statistics. Its purpose is to capture the range and diversity of mental models, not to make claims about the percentage of people expressing them (Cross, 2005; Stainton Rogers, 1995). In this sense, also minority opinions-which should be not of less importance-find their way into research. Second, and related to the previous point, the analytical focus of Q-methodology remains exclusively on clustering individuals' perception. It, therefore, does not provide large-scale generalizable results alongside a positivistic understanding where the proportion of individuals subscribing to a point of view is deemed important and where different demographic and otherwise parameters are analyzed for making further inferences (Zabala \& Pascual, 2016). Let us turn to a description of the methodological steps followed in this Q-methodology study. 


\subsection{Concourse}

In most cases, Q-methodology studies start with the concourse, which is an initial collection and ordered presentation of statements about the topic of interest-similarly to the design of a questionnaire. However, different from typical survey-based research, the concourse must not be theoretically-driven. Rather it must reflect the phenomenon of study in a broad and engaging manner (Watts \& Stenner, 2012). Following William Stephenson (1993) "[...] a distinction has to be drawn between matters of objective fact [...] which are singular bits of information which do not spread, and matters of self-reference, which are infinite about anything." In theory, therefore any collection of statements, no matter how large, is still a subset of an infinite number of possible statements about a phenomenon (McKeown \& Thomas, 2013). There is no correct or universal mode to determine the right number and content of statements.

In line with Stainton Rogers (1995), who suggested a range of approximately 40-80 statements for a concourse, our initial list comprised 45 statements. As we discussed previously, due to the lack of specific studies surrounding our phenomenon of interest, we were forced to not only take into consideration scholarly sources, but also recent news articles, science and technology magazines, personal blogs, or websites of device manufacturers and software developers for formulating an initial set of statements, which could fuel a stimulated debate about physiolytics at the workplace and as such reproduce different opinions and discourses about the topic.

\section{$3.2 \quad$ Q-sample}

Since prior research has shown that conducting interviews with domain experts or people with a special interest increases the probability of reaching a representative sample (Dennis, 1988), we conducted 12 open-ended interviews with experts in the field of public health, preventive medicine, and IT-enabled health promotion in Switzerland-the originating country of this study (cf. Table A1 for sample characteristics). A certain level of familiarity with regards to e-health and IT-based wellness programs was required so that a domain expert was considered as interview partner. Selected experts were contacted by telephone and subsequently recruited by applying the "snowballing" technique, as described by Myers and Newman (2007). Each interview lasted approximately one hour and was recorded with the consent of the expert. Allowing a certain flexibility and openness during the interviews, we talked through each 
statement, asked for its relation to the affordances and constraints identified in the literature, as well as discussed missing perspectives.

We performed a theoretical coding to assure a systematic coverage of all possible perspectives on physiolytics use at the workplace and that the selected Q-sample "contains the comprehensiveness of the larger process being modeled" (S. R. Brown, 1993). In doing so, statements that experts found to be similar or inverse in meaning were merged or redundant statements discarded in order to address all identified affordances and constraints with our configuration. The final Q-sample consisted of 32 statements, out if which 16 statements represent affordances and the other 16 constraints. Each statement was randomly assigned to a number. Figure 1 depicts the hierarchical tree of codes. The nodes represent affordances and constraints, to which we assigned the individual statements of the Q-sample (\#1-\#32). The leaves of the coding tree constitute the different affordances $\left(\mathrm{AFF}_{1}-\mathrm{AFF}_{4}\right)$ and constraints $\left(\mathrm{CON}_{1}-\mathrm{CON}_{4}\right)$ from the literature review in Section 2.2. The two internal nodes (AFF and CON) characterize general aspects that apply to all affordances or, respectively, to all constraints.

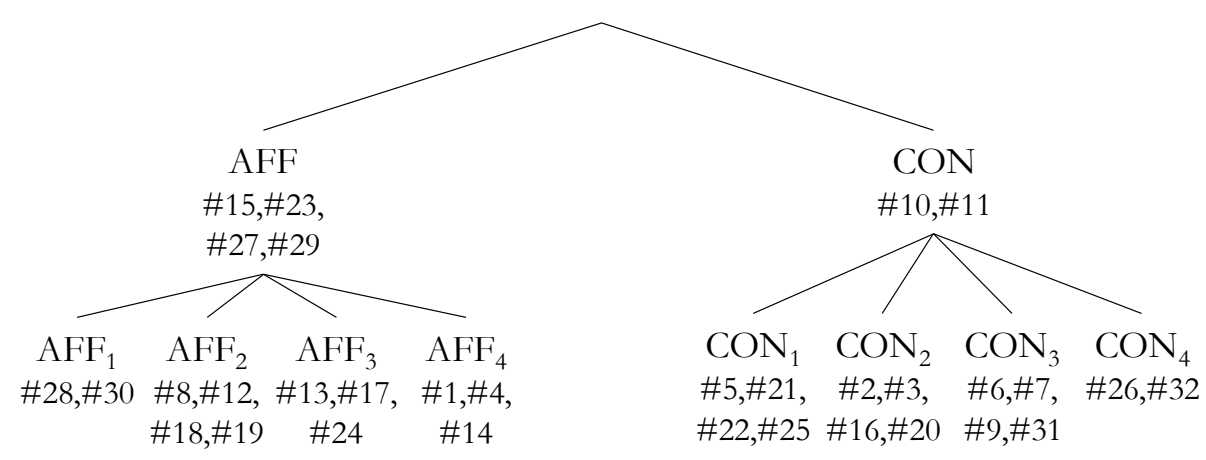

Figure. 1. Tree of codes and assignment of Q-sample statements

(Note: AFF : affordance, CON : constraint, \# : assigned number of a statement)

\subsection{Q-sorting}

The core of Q-methodology represents the sorting exercise, named Q-sorting, that is used for eliciting a person's subjective perspective on the phenomenon of interest (Donner, 2004). To recruit respondents for this third step in our study, we followed a purposive sampling strategy (Tashakkori \& Teddlie, 2003) by advertising the study on our institutional website and actively contacting individuals by e-mail from which we knew that they will face the introduction of 
digital corporate wellness programs at their workplace. These measures could range from the distribution and voluntary use of fitness trackers without any organizational supervision to more sophisticated and coercive scenarios, such as using smartwatches or biosensors together with some sort of integrated visualization software for unattributed analyses of the data on team level. In total, 20 individuals were invited to take part in the Q-sorting exercise. The minimum age was 20 and the maximum 63 years with an average of 35.5 years. 65 percent were female and 35 percent male. Each person was employed at a different organization (all located in Switzerland), with 55 percent working at large corporations, 35 percent at a public organization, and 10 percent at a small or medium-sized company (cf. Table A1 for sample characteristics). However, it is important to note that in Q-methodology the sampling of respondents is not key to the process (Shemmings, 2006). While in traditional correlational analyses tests are applied to a sample of people, Q-methodology applies persons to a "sample" of statements, or, more accurately, their action upon a sampling of elements (Q-sorting), which will be correlated and subsequently factored (Stainton Rogers, 1995).

The Q-sorting was performed online. Each respondent was sent a personalized link to the $Q$ sortware platform with specific information about the goals of the study and instructions how to perform the sorting. The Q-sorting consisted of two distinct steps: First, the respondents randomly received one Q-sample statement at a time and were asked to drag-and-drop each card into one of three piles (i.e. agree, disagree, or neutral). After the respondents completed the initial sorting stage, they were given the choice to review their piles and make changes or to continue. Second, the participants were asked to perform a rank-ordering, with possible ranking values ranging from +4 for items that are "most agreeable" in the view of a particular participant, through 0 for "indifference", to -4 for items that are considered "most disagreeable". For reasons of simplicity and pragmatism (R. Baker et al., 2014; Valenta \& Wigger, 1997), they were asked to put the statement with which they most agreed and most disagreed in the designated box first; then the second most agreed/disagreed statements and so on, until all slots in the predefined quasi-normal distribution table are filled (cf. Figure A1 in the Appendix). This is done, so that the number of possible configurations of cards is reduced, making the rankordering of opinion statements easier for participants (Watts \& Stenner, 2012).

\subsection{Quantitative data analysis}


The fourth step in Q-methodology studies is the analysis of the qualitative data by using a quantitative approach; commonly principal component analysis (PCA) or exploratory factor analysis (EFA) (McKeown \& Thomas, 2013; Zabala, 2014). For performing the quantitative analysis based on the results from the sorting exercise, we used STATA software package, version 13.1. Microsoft Excel was used for additional visual analyses.

As discussed before, unlike the typical application of factor analysis, where the respondents are placed in rows and their responses to the statements are placed in columns, Q-methodology is concerned with analyzing the by-person correlation (Watts \& Stenner, 2012). Accordingly, factor analysis is applied to determine a set of factors onto which the respondents load on the basis of the item configurations (Q-sorts) they have created-as opposed to identifying patterns that are inherent in the answers of the respondents. ${ }^{2}$

Watts and Stenner (2012) recommend using PCA with Varimax rotation to calculate these factors and to pursue a rotated solution, which maximizes the amount of variance explained by the extracted factors. They propose to only choose factors with eigenvalue 1.00, while McKeown and Thomas (2013) suggest to also reflect theoretical and practical considerations for the determination of the total number of factors to be included in the study: A factor must ordinarily have at least two Q-sorts that load significantly upon it alone (Watts \& Stenner, 2012). Following McKeown and Thomas (2013) significance at the $\mathrm{p}<.01$ level is achieved when a factor loading is greater than 2.58 times the standard error for the loading, which is calculated as $1 / \mathrm{N}$, where $\mathrm{N}$ is the number of statements. Alternatively, Donner (2004) suggests that respondents were considered to define a factor when they load approximately 0.45 (or greater) on a single factor. Overall, the obtained solution accounts for $71.4 \%$ of the total variance, which is a fairly good approximation. Both criteria, i.e. the eigenvalue and minimum number of Q-sorts requirement, were met: As shown in Table A1 in the Appendix, each factor has an eigenvalue above 1.00 and is composed of at least three Q-sorts.

\subsection{Interpretation of quantitative findings}

\footnotetext{
${ }^{2}$ Practically speaking, this means that each record obtained from QSortware had to be transposed, with statements in rows and participants in columns, before used to perform a PCA in a statistical software package like STATA.
} 
As we mentioned above, Q-methodology is different from other techniques as it neither looks for representative sampling of respondents nor imposes any a priori meaning to the questions being asked. Instead, it lets respondents decide what does (and what does not) have value from their perspective (Watts \& Stenner, 2012). According to Steven R Brown (1980), it is the task of the researcher to attribute significance a posteriori through interpretation, rather than through a priori postulation. In Q-methodology, this sense-making process is typically limited to the determination of the range and diversity of shared viewpoints related to the phenomenon of interest (what do people think), for example, by comparing and contrasting the rankings of factor scores as well as the degree of consensus or disagreement regarding specific statements (Dziopa \& Ahern, 2011). ${ }^{3}$ However, the resulting interpretations do not provide any causal explanation for the emergence of a mental model (why do people think in this way). In presenting our research findings, which we elaborate next, we will slightly deviate from the usual approach of interpreting viewpoints only and to a certain extent also provide alternative explanations how our overall results can be explained and related to the current discourse in IS research.

\section{$4 \quad$ Mental models of physiolytics}

As we mentioned above, Q-methodology is a particularly suitable method for determining the range and diversity (not the structure or causality) of mental models that people construct in order to make sense of complex phenomena in their lives. It is, however, important to note that we need to differentiate between the user's real mental models and the researcher's conceptualized interpretation of what he or she thinks how the user perceives a technology (Donald A Norman, 2014). The latter is invented to provide an appropriate (in the sense of being accurate, consistent, and complete) representation of a user's worldview, while the former is often "imprecisely specified, and full of inconsistencies, gaps and idiosyncratic quirks" (ibid., p.9). The five distinct mental models, which resulted from our analysis, demonstrate many contradictions but also some commonalities in users' thought patterns (cf. Table A2). For instance, all user groups express a cautious, somewhat hesitant attitude toward the employer's

\footnotetext{
${ }^{3}$ Consensus or distinguishing items are typically those three or four statements with smallest or largest variance in response across all identified factors.
} 
intrusion into matters of personal privacy and self-determination or highlight the importance of a voluntary nature of participation. Emphasizing constraints over affordances of physiolytics is dominant in all groups, too. At the same time, the mental models considerably differ in the degree to which certain affordances are perceived or not. Let us now turn to the peculiarities of each mental model.

\subsection{The freedom-loving user type}

Most of the respondents share a mental model that weights personal freedom and individuality much higher than control or conformity with organizational goals. Overall, people belonging to this group of users can be characterized by a strong resistance against organizational interference into personal matters and a high level of concern regarding the misuse of personal information. They have a strong preference toward corporate wellness programs, in which participation and information disclosure is voluntary.

What affordances and constraints are dominant: Freedom-loving users perceive physiolytics as solutions that should primarily be designed for the purpose of increasing awareness and cognition of work-related issues with health and well-being or which help them to counter unhealthy work habits. In doing so, these solutions should by no means restrict their personal autonomy in taking self-contained and bold decisions at work. Table 5 shows the statements, which the members of this user type agree and disagree with most.

Table 5. Statements with highest and lowest agreement

\begin{tabular}{|c|c|c|c|c|c|c|}
\hline No. & Description & $\mathrm{U}_{1}$ & $\mathbf{U}_{2}$ & $\mathrm{U}_{3}$ & $\mathbf{U}_{4}$ & $\mathbf{U}_{5}$ \\
\hline 27 & $\begin{array}{l}\text { Algorithmic decision-making tools for health prevention at work need to } \\
\text { afford primarily benefits to employees. }\end{array}$ & 4 & 1 & -1 & 0 & 1 \\
\hline${ }^{\circ} 7$ & $\begin{array}{l}\text { The best way to reduce stress-related absences is to prohibit the cash out } \\
\text { of overtime and vacation days. }\end{array}$ & 3 & -2 & 2 & 3 & -1 \\
\hline 17 & I don't need a tool to tell me when I feel sick or stressed out. & 3 & 2 & 1 & 2 & -1 \\
\hline${ }^{\mathrm{x}} 20$ & $\begin{array}{l}\text { The use of such algorithmic decision-making tools within the scope of } \\
\text { health prevention at work should be completely voluntary. }\end{array}$ & 3 & 4 & 3 & 3 & 2 \\
\hline 4 & $\begin{array}{l}\text { I don't fear to share my personal information with my employer for the } \\
\text { purpose of performance appraisals. }\end{array}$ & -3 & 0 & -1 & -3 & -2 \\
\hline 24 & $\begin{array}{l}\text { It is hard for me to determine my health status accurately without the help } \\
\text { of technology. }\end{array}$ & -3 & -3 & -2 & -1 & -1 \\
\hline${ }^{x} 28$ & $\begin{array}{l}\text { I would like to be monitored during all my job activities, knowing that it's } \\
\text { done for the matter of my personal health. }\end{array}$ & -3 & -4 & -4 & -2 & -4 \\
\hline
\end{tabular}




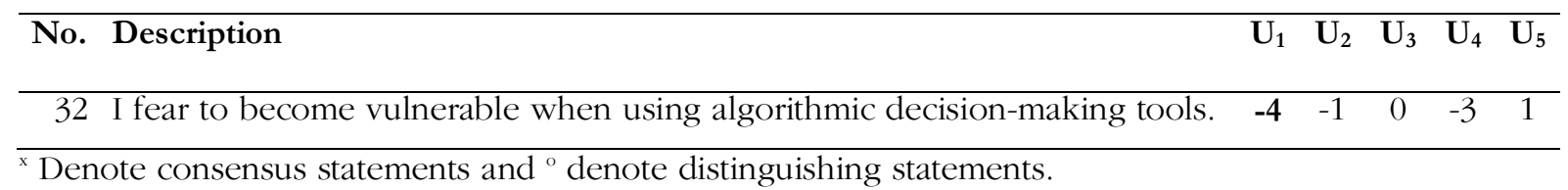

Implications for implementing physiolytics in organizations: Self-reliance and personal responsibility for one's actions are central in this mental model. In this sense, a solution that detects deviations from a "desired behavior" and that prescribes how one should execute certain tasks (Koskimäki et al., 2009) would not be appreciated. In fact, this would rather lead to a negative effect on an employee's job motivation and performance (Lawrence \& Robinson, 2007). Considering that users' appraisals of a new IT system primarily depend on their perceptions of opportunities and threats and the level of control users have over the system (Beaudry \& Pinsonneault, 2005; Elie-Dit-Cosaque \& Straub, 2011), managers in charge for implementing physiolytics should stress the following aspects. Arguing that these solutions afford to reduce harmful or potentially dangerous work-related events or might help to uncover safety violations would probably be futile. Moreover, if physiolytics is introduced as a voluntary measure for workplace enjoyment and enrichment with the goal to enhance health awareness (and detached from any job optimization or performance appraisal), the use intention might increase significantly.

\subsection{The individualist user type}

Similar to the freedom-loving users, members of the second group have a desire that personal and business matters remain separate. However, although they share the same opinion concerning this particular point, they are different from the previous user type as they put a higher emphasis on the individual responsibility of one's actions. More than the other user types, individualists believe that health and well-being are personal and as such should not be "digitized" and "institutionalized" in any form by their employer. Even if the organization incentivizes the introduction of physiolytics, they probably would not be part of the program as they have a particularly strong anxiety that the employer may use personal information against them.

What affordances and constraints are dominant: The mental model of individualists is particularly affected by possible constraints that physiolytics imposes to them. Keeping the 
authority of making own choices (may it be good or bad ones) without having to legitimate and adapt unhealthy work practices or to share personal information with the collective is a fundamental condition for this user type to use physiolytics. Interestingly, they are not per se against the adoption of this technology, in the case it helps them to improve their health. However, they are skeptical about the claim that physiolytics could achieve this promise. Table 6 shows the statements that individualist users agree and disagree with most.

Table 6. Statements with highest and lowest agreement

\begin{tabular}{|c|c|c|c|c|c|c|}
\hline No. & Description & $\mathrm{U}_{1}$ & $\mathrm{U}_{2}$ & $\mathrm{U}_{3}$ & $\mathbf{U}_{4}$ & $\mathbf{U}_{5}$ \\
\hline${ }^{\mathrm{x}} 20$ & $\begin{array}{l}\text { The use of such algorithmic decision-making tools within the scope of } \\
\text { health prevention at work should be completely voluntary. }\end{array}$ & 3 & 4 & 3 & 3 & 2 \\
\hline 16 & $\begin{array}{l}\text { I'm fully responsible for my health; the company should not worry about } \\
\text { that. }\end{array}$ & 1 & 3 & 1 & 1 & -3 \\
\hline${ }^{\circ} 25$ & $\begin{array}{l}\text { I believe that private (such as health) and business matters need to remain } \\
\text { strictly separated. }\end{array}$ & 1 & 3 & 0 & 4 & -3 \\
\hline 26 & $\begin{array}{l}\text { There should be no peer pressure when it comes to using algorithmic } \\
\text { decision-making tools for health prevention at work. }\end{array}$ & 1 & 3 & 1 & 1 & 0 \\
\hline 10 & $\begin{array}{l}\text { I would only use such an algorithmic decision-making tool, if I would } \\
\text { financially get recompensed by the company. }\end{array}$ & -1 & -3 & -3 & -4 & -1 \\
\hline${ }^{\mathrm{x}} 11$ & $\begin{array}{l}\text { I would only use such an algorithmic decision-making tool, if I would get } \\
\text { more leaves by the company. }\end{array}$ & -1 & -3 & -2 & -3 & -3 \\
\hline 24 & $\begin{array}{l}\text { It is hard for me to determine my health status accurately without the help } \\
\text { of technology. }\end{array}$ & -3 & -3 & -2 & -1 & -1 \\
\hline${ }^{x} 28$ & $\begin{array}{l}\text { I would like to be monitored during all my job activities, knowing that it's } \\
\text { done for the matter of my personal health. }\end{array}$ & -3 & -4 & -4 & -2 & -4 \\
\hline
\end{tabular}

${ }^{\mathrm{x}}$ Denote consensus statements and ${ }^{\circ}$ denote distinguishing statements.

Implications for implementing physiolytics in organizations: Fundamentally opposed to the "selftracking culture" (Wolf, 2009), members of this group of users do not appreciate publicly sharing personal data nor do they believe that it will foster more participatory and collaborative forms of working. In their mental model, the unprecedented transparency of one's health (and other) indicators will rather lead to a culture of notorious comparison of "heroes" and "heroines" and intensify the pressure (or create a moral obligation) to adjust one's behavior to be more socially adapted or institutionally desired (Luik, 1999). Accordingly, trying to explain the possible affordances of physiolytics from a social or group perspective, will probably not lead to a change of mind. In order to stimulate an opportunity-oriented appraisal of physiolytics systems, 
managers of physiolytics initiatives should rather highlight aspects related to procedural fairness and non-discrimination, as the individualist users are particularly sensitive to threats against their individuality.

\subsection{The cynical user type}

People belonging to this third group of users manifest a perception of "seeing through the espoused goals of the implementers" (Selander \& Henfridsson, 2012). While cynical users share the same aversion of being monitored at the workplace as the prior discussed user groups, they seem to have a larger cognitive distance to the plans of their employer and question the "communicated reasons" (respectively believe to know the "real reasons") why physiolytics is introduced in their organization.

What affordances and constraints are dominant: People sharing this mental model strongly reject the idea of being part of a big surveillance apparatus. In their view, the introduction of physiolytics is nothing but an argumentative deception strategy of organizations to obtain more data to surveil and manipulate employees. Consequently, they do tend to paint a bleak picture of the role of physiolytics in improving the working environment in any kind. An alternative, more optimistic interpretation could be that their strong constraint bias and negation of affordances is owing to a limited and perhaps mistaken understanding of physiolytics and related design features. The statements, which cynical users agree and disagree with most, are shown in the subsequent Table 7.

Table 7. Statements with highest and lowest agreement

\begin{tabular}{|c|c|c|c|c|c|c|}
\hline No. & Description & $\mathrm{U}_{1}$ & $\mathbf{U}_{2}$ & $\mathrm{U}_{3}$ & $\mathrm{U}_{4}$ & $\mathbf{U}_{5}$ \\
\hline${ }^{\circ} 1$ & $\begin{array}{l}\text { Assessments of employees (including health-related) should be performed } \\
\text { by personal observations from managers and not by a surveillance system. }\end{array}$ & 2 & 1 & 4 & 0 & -2 \\
\hline 2 & I fear that we will be monitored $24 / 7$ soon. & 0 & 0 & 3 & 0 & -2 \\
\hline${ }^{\circ} 3$ & $\begin{array}{l}\text { Analyzing personal information is a way of the company to manipulate } \\
\text { actions and opinions. }\end{array}$ & -2 & -2 & 3 & -2 & 1 \\
\hline${ }^{\mathrm{x}} 20$ & $\begin{array}{l}\text { The use of such algorithmic decision-making tools within the scope of } \\
\text { health prevention at work should be completely voluntary. }\end{array}$ & 3 & 4 & 3 & 3 & 2 \\
\hline 5 & I regularly disclose personal information on social networks. & 0 & -2 & -3 & 1 & 0 \\
\hline 10 & $\begin{array}{l}\text { I would only use such an algorithmic decision-making tool, if I would } \\
\text { financially get recompensed by the company. }\end{array}$ & -1 & -3 & -3 & -4 & -1 \\
\hline 18 & $\begin{array}{l}\text { I'm generally open to try algorithmic decision-making tools that help me to } \\
\text { stay healthy at work. }\end{array}$ & 0 & 2 & -3 & -2 & 1 \\
\hline
\end{tabular}




\begin{tabular}{|c|c|c|c|c|c|}
\hline No. Description & $\mathrm{U}_{1}$ & $\mathbf{U}_{2}$ & $\mathbf{U}_{3}$ & $\mathbf{U}_{4}$ & $\mathbf{U}_{5}$ \\
\hline $\begin{array}{l}{ }^{x} 28 \text { I would like to be monitored during all my job activities, knowing that it's } \\
\text { done for the matter of my personal health. }\end{array}$ & -3 & -4 & -4 & -2 & -4 \\
\hline
\end{tabular}

${ }^{\mathrm{x}}$ Denote consensus statements and ${ }^{\circ}$ denote distinguishing statements.

Implications for implementing physiolytics in organizations: It is not an easy task to bring around a cynical user to see some good in physiolytics. In a way, their mental model expresses a strong desire to subvert and undermine managerial control mechanisms (Gabriel, 1999). More than that, Selander and Henfridsson (2012) describes cynicism as a form of passive resistance which could easily escalate and feed new waves of resistance among other users. Accordingly, Lapointe and Rivard (2005) suggest to dig deeper and look for the reasons how and why resistance surfaces, progresses, and culminates. Discussing concrete affordances and constraints, instead of losers and winners of the introduction of physiolytics, could be a reasonable way to sanitize the discourse and to avoid a threat-biased appraisal of physiolytics systems.

\subsection{The tech-independent user type}

Individuals having this mental model have a particular fear of losing the ability to act independently without the help of technology. Accordingly, instead of implementing and appropriating a complex technology into their daily work routines, they prefer "conventional" measures of stress prevention or health promotion at the workplace (e.g. reducing the daily workload, prohibiting the cash out of vacation days, or conducting vocational trainings that help workers to shape their awareness about health and safety risks).

What affordances and constraints are dominant: People with this mental model are particularly concerned that physiolytics will substitute human empathy and judgment. Similar to individualist users, they do not believe that physiolytics will enable them to improve their health and wellbeing-not because the technology is incapable of affording this, but rather because they do not need it or do not want to be restrained by an algorithm telling them when, how, and what to do. They also share the same negative attitude as freedom-loving users toward an employer's intrusion into matters of personal privacy and self-determination. In the same vein, not because they fear to become vulnerable to organizational sanctions and penalties, but rather because the role of technology will get more prominent in their daily lives. Table 8 shows the statements, which the members of this user type agree and disagree with most. 
Table 8. Statements with highest and lowest agreement

\begin{tabular}{|c|c|c|c|c|c|c|}
\hline No. & Description & $\mathrm{U}_{1}$ & $\mathbf{U}_{2}$ & $\mathrm{U}_{3}$ & $\mathbf{U}_{4}$ & $\mathrm{U}_{5}$ \\
\hline${ }^{\circ} 25$ & $\begin{array}{l}\text { I believe that private (such as health) and business matters need to remain } \\
\text { strictly separated. }\end{array}$ & 1 & 3 & 0 & 4 & -3 \\
\hline${ }^{\circ} 7$ & $\begin{array}{l}\text { The best way to reduce stress-related absences is to prohibit the cash out } \\
\text { of overtime and vacation days. }\end{array}$ & 3 & -2 & 2 & 3 & -1 \\
\hline 8 & $\begin{array}{l}\text { Vocational trainings are more effective means to reduce the risk of stress- } \\
\text { related absences than algorithmic decision-making tools. }\end{array}$ & -1 & -2 & 1 & 3 & 0 \\
\hline${ }^{\mathrm{x}} 20$ & $\begin{array}{l}\text { The use of such algorithmic decision-making tools within the scope of } \\
\text { health prevention at work should be completely voluntary. }\end{array}$ & 3 & 4 & 3 & 3 & 2 \\
\hline 4 & $\begin{array}{l}\text { I don't fear to share my personal information with my employer for the } \\
\text { purpose of performance appraisals. }\end{array}$ & -3 & 0 & -1 & -3 & -2 \\
\hline${ }^{\mathrm{x}} 11$ & $\begin{array}{l}\text { I would only use such an algorithmic decision-making tool, if I would get } \\
\text { more leaves by the company. }\end{array}$ & -1 & -3 & -2 & -3 & -3 \\
\hline 32 & I fear to become vulnerable when using algorithmic decision-making tools. & -4 & -1 & 0 & -3 & 1 \\
\hline 10 & $\begin{array}{l}\text { I would only use such an algorithmic decision-making tool, if I would } \\
\text { financially get recompensed by the company. }\end{array}$ & -1 & -3 & -3 & -4 & -1 \\
\hline
\end{tabular}

${ }^{\mathrm{x}}$ Denote consensus statements and ${ }^{\circ}$ denote distinguishing statements.

Implications for implementing physiolytics in organizations: If we understand people that share this mental model as what Rogers (1962) called "laggards", there are two options to explore. A pessimistic approach would be to simply ignore them because it is futile to praise the affordances of a technological artifact. A more positive and active response would be to increase the share of physiolytics supporters (that probably originate from one of the other groups). According to Rogers (1962), the perception of laggards might change when they are surrounded by peers who have already adopted and who are satisfied with the solution. However, if we interpret this mental model as a manifestation of technophobia (Brosnan, 2002), managers of physiolytics initiatives need measures that help to reduce anxiety and that motivate an opportunity-oriented appraisal of physiolytics at the workplace.

\subsection{The balancer user type}

In contrast to the other mental models, the balancer user type perceives many affordances of physiolytics. They signal a willingness to use physiolytics when it offers them the possibility to 
enhance awareness and cognition of work-related health issues. However, like freedom-loving users, a certain amount of skepticism is present since they fear losing the sovereignty over personal and sensitive data.

What affordances and constraints are dominant: Different from others, individuals belonging to this group of users share the belief that the employer, to some extent, is responsible for health and well-being at the workplace. It is, therefore, the obligation of the organization to care for a safe and secure work environment and to instruct employees regarding healthy work practice. Given that their privacy is not constrained and their data not repurposed for other organizational goals, they express a higher propensity of using physiolytics than others if the employer decides to introduce this technology. Table 9 shows the statements, which balancing users agree and disagree with most.

Table 9. Statements with highest and lowest agreement

\begin{tabular}{|c|c|c|c|c|c|c|}
\hline No. & Description & $\mathrm{U}_{1}$ & $\mathbf{U}_{2}$ & $\mathrm{U}_{3}$ & $\mathbf{U}_{4}$ & $\mathbf{U}_{5}$ \\
\hline${ }^{\circ} 21$ & $\begin{array}{l}\text { I fear that someone could abuse my personal information for other } \\
\text { purposes. }\end{array}$ & -2 & -1 & 0 & 0 & 4 \\
\hline 12 & $\begin{array}{l}\text { I would like to use algorithmic decision-making tools, which support me to } \\
\text { become healthier in my free time. }\end{array}$ & 0 & 2 & -1 & 0 & 3 \\
\hline 13 & Such technologies really help people to adopt healthier life choices. & 2 & -1 & 0 & -1 & 3 \\
\hline 15 & $\begin{array}{l}\text { I believe that algorithmic decision-making tools afford employers more } \\
\text { than to the employees. }\end{array}$ & -1 & -1 & 2 & 1 & 3 \\
\hline${ }^{\mathrm{x}} 11$ & $\begin{array}{l}\text { I would only use such an algorithmic decision-making tool, if I would get } \\
\text { more leaves by the company. }\end{array}$ & -1 & -3 & -2 & -3 & -3 \\
\hline 16 & $\begin{array}{l}\text { I'm fully responsible for my health; the company should not worry about } \\
\text { that. }\end{array}$ & 1 & 3 & 1 & 1 & -3 \\
\hline${ }^{\circ} 25$ & $\begin{array}{l}\text { I believe that private (such as health) and business matters need to remain } \\
\text { strictly separated. }\end{array}$ & 1 & 3 & 0 & 4 & -3 \\
\hline${ }^{\mathrm{x}} 28$ & $\begin{array}{l}\text { I would like to be monitored during all my job activities, knowing that it's } \\
\text { done for the matter of my personal health. }\end{array}$ & -3 & -4 & -4 & -2 & -4 \\
\hline
\end{tabular}

${ }^{x}$ Denote consensus statements and ${ }^{\circ}$ denote distinguishing statements.

Implications for implementing physiolytics in organizations: Balancing users comprehend that physiolytics could unfold certain positive effects on their work environment. However, there is a delicate weighing against privacy risks related to the disclosure of sensitive personal information, which in the literature is referred to as privacy calculus (Dinev \& Hart, 2006). Managers of physiolytics initiatives may adopt several approaches to increase the likelihood that 
a balancing user's privacy calculus results in a positive appraisal. Physiolytics solutions may foster mechanisms of self-protection through privacy-enhancing features that enable employees to control the access to and use of their personal information (Xu, Teo, Tan, \& Agarwal, 2012). A second approach is to strengthen an employee's trust in the system operator, for example through external privacy certifications that signal the system operator's willingness to protect personal information (Van Slyke, Shim, Johnson, \& Jiang, 2006). Further, establishing affective commitment that pertains to the employee's involvement and organizational responsibility may lead to a stronger emphasis on perceived affordances (Kordzadeh, 2014).

\section{Discussion}

In this paper, we set out to investigate what affordances and constraints do employees associate with the use of physiolytics in their occupational environment. Synthesizing literature on wearables and especially on physiolytics, we conducted a Q-methodology study to reveal distinct mental models that individuals form to make sense of this technology (Mettler et al., 2017). Based on the action potentials and limitations our respondents perceived, we describe five basic viewpoints on physiolytics serving to address the need for opening up the "user black box" in understanding the wider implications and possible user responses to the introduction of wearable technologies in the workplace (Juhani Iivari \& Iivari, 2011; J. Iivari et al., 2010). In what follows, and given that Q-methodology does not provide any explanations why and how certain mental models come into being, we would like to offer some suggestions for placing our results in a wider context.

Let us start with remarking that our overall findings resonate well with recent research taking on the "dark side" of IT use. As we mentioned above, there is a considerable emphasis on constraints across all mental models. The limiting factors shaped the worldviews of our respondents much more than the action potentials. This is in line with prior studies (Breward et al., 2017; Warkentin, Goel, \& Menard, 2017) which showed that there is a predisposition to view emerging and/or controversial solutions with greater skepticism and worry as when risks and returns are more predictable to users. All mental models we discovered exhibit a certain level of controversy and hesitant attitude towards physiolytics, since multiple constraints become salient in the people's appraisals. Focusing only on the positive effects of emerging technologies 
(or using a techno-enthusiasm rhetoric), as common in earlier IS studies (Cazier, Jensen, \& Dave, 2008), would obviously result in a poor explanation of physiolytics use.

As with any surveillance and tracking technology, privacy concerns play a particularly important role in the presented application scenarios of physiolytics (Li et al., 2016). In this regard, many studies dealing with privacy and information disclosure (Dinev \& Hart, 2006; Gao et al., 2015) purport the idea that individuals perform a kind of cost-benefit analysis to see if the advantages of wearables are equal to or superior to the potentials privacy risks from using this technology. Our findings affirm but also extend this notion as we show that employees, apart from privacy concerns, also take other risk factors into account when thinking about the use of physiolytics in occupational settings. For example, our respondents perceived constraints on their personal freedom and individuality and how these may impose a new, more socially or institutionally desired work ethic and, as a result, negatively influence their margin of taking unique, creative, and self-contained decisions at work. This is unfortunate given that a loss of autonomy may lead to reduced job-motivation or even resistance (Lawrence \& Robinson, 2007). In addition, some respondents also perceived major threats from an over-dependency on technology and the deprivation of human analytical skills. This is again worrisome because this frequently redounds to an overestimation of a technology's action potentials (Parasuraman \& Manzey, 2010), thereby frequently hindering the meaningful interpretation and reflection of the actual affordances.

The controversial and disruptive nature of physiolytics also leads to a considerable heterogeneity in the perceptions of affordances and constraints. Following Mukhopadhyay, Rajiv, and Srinivasan (1997), a technology's disruptiveness manifests in substantial changes of work processes. The introduction of physiolytics at the workplace, as demonstrated by exemplary prototypes in Table 1, exhibits features of disruptiveness due to the fact that it may significantly impact the design and execution of certain work activities (Cheng et al., 2013; Valero et al., 2016) and social structure among employees (Chung \& Danis, 2016; Gorm \& Shklovski, 2016; Vyas et al., 2015). Given that some of the presented applications scenarios entail severe organizational and cultural changes, considerable insecurities and unpredictable employee behavior could result (Elie-Dit-Cosaque \& Straub, 2011; Lapointe \& Rivard, 2005). While some workers may perceive such a technology as an opportunity, others primarily see threats to their personal situation (Beaudry \& Pinsonneault, 2005; Fadel \& Brown, 2010). Differing opportunity 
perception manifests in whether or not a user's mental model emphasizes affordances. Likewise, variance in threat perception becomes evident through a differing role of physiolytics constraints in the mental models. While, for example, cynical users are characterized by an extreme accentuation of constraints, balancer user exhibit a rather low emphasis on constraints.

The results of our study also break with conventional approaches which prefer to differentiate users by deterministic variables, such as age, sex and marital status (Koo, 2017). While we believe that such a differentiation is practical and, to a certain extent, helpful in untangling user interests, we would rather encourage a socio-cognitive sensemaking approach (Nambisan, Lyytinen, Majchrzak, \& Song, 2017) that is centered on understanding the differences in perception of affordances and constraints and their relative importance for use decisions. For instance, the fear of personal information abuse that is particularly salient for freedom-loving and individualist user types may render physiolytics affordances unimportant for the use decision.

In addition, our affordance-theoretic perspective of user mental models in physiolytics may enrich current knowledge on user technology perceptions and thus opens up the "user black box". Many studies refer to coping theory (Lazarus \& Folkman, 1984) in order to explain an individual's socio-cognitive sensemaking process while approaching a technology. These studies distinguish IS appraisals by whether users primarily perceive system opportunities or system threats and by whether or not a user sees viable coping options (Beaudry \& Pinsonneault, 2005; Elie-Dit-Cosaque \& Straub, 2011). By employing an affordance theoretical perspective, we explore user mental models for IS appraisal and find that, for the context of physiolytics at the workplace, these models exhibit differing emphases on specific action potentials and ability confinements (Majchrzak \& Markus, 2012; Volkoff \& Strong, 2013). Thus, our results motivate a fine granular perspective on user mental models for IS appraisal. This may enrich the current understanding of the conditions, under which users choose or modify IS responses (Anol Bhattacherjee et al., 2017). For example, the cynical and the individualist user type may both react negatively to physiolytics offerings, however for very different reasons. While improving procedural fairness and protection against discrimination may lead to positive responses of individualist users, it will most certainly not dissolve the cynical users' resentments. 


\section{Conclusion and future research}

With the introduction of physiolytics and the blurring boundaries between work and private life, employees are facing unprecedented opportunities but also many risks. A rethinking of how wearables (originating from private use contexts) should be introduced in occupational settings and a nuanced comprehension of user concerns is needed. Since physiolytics solutions not only collect and analyze job-related data but also highly personal information, it is of utmost importance to get a detailed understanding about the preoccupations of users and antecedents of use (Agarwal \& Prasad, 1998; Nevo \& Wade, 2007). The presented mental models are but a first attempt in providing a contextual envelope for explanatory and design-oriented research and for instigating an ethical debate about the limits and benefits of digital wellness programs. Certainly, this paper leaves many avenues for future research following different study designs and research philosophies. For example, variance-centered experiments for measuring the effects of certain stimuli on usage intention for different user groups; or qualitative studies for calibrating and replicating our Q-methodology results. We also hope that our paper will stimulate other researchers to consider Q-methodology in their work and to delve into the complex dynamics and controversial nature of wearables and physiolytics in particular.

\section{Acknowledgement}

This research has been supported by the Swiss National Science Foundation (SNSF) grant no. 172740.

\section{References}

Agarwal, R., \& Prasad, J. (1998). The antecedents and consequents of user perceptions in information technology adoption. Decision Support Systems, 22(1), 15-29.

Alahäivälä, T., \& Oinas-Kukkonen, H. (2016). Understanding persuasion contexts in health gamification: A systematic analysis of gamified health behavior change support systems literature. International Journal of Medical Informatics, 96, 62-70.

Al-Natour, S., \& Benbasat, I. (2009). The adoption and use of IT artifacts: A new interactioncentric model for the study of user-artifact relationships. Journal of the Association for Information Systems, 10(9), 661-685. 
Armatas, C. A., Venn, T. J., \& Watson, A. E. (2014). Applying Q-methodology to select and define attributes for non-market valuation: A case study from Northwest Wyoming, United States. Ecological Economics, 107, 447-456.

Bagozzi, R. P. (2007). The legacy of the technology acceptance model and a proposal for a paradigm shift. Journal of the Association for Information Systems, 8(4), 244-254.

Baker, R., Thompson, C., \& Mannion, R. (2006). Q methodology in health economics. Journal of Health Services Research \& Policy, 11(1), 38-45.

Baker, R., Wildman, J., Mason, H., \& Donaldson, C. (2014). Q-ing for health—A new approach to eliciting the public's views on health care resource allocation. Health Economics, 23(3), $283-297$.

Beaudry, A., \& Pinsonneault, A. (2005). Understanding user responses to information technology: A coping model of user adaptation. MIS Quarterly, 29, 493-524.

Bhattacherjee, A., Davis, C. J., Connolly, A. J., \& Hikmet, N. (2017, Forthcoming). User response to mandatory IT use: A cop- ing theory perspective. European Journal of Information Systems, 1-20.

Bhattacherjee, A., \& Premkumar, G. (2004). Understanding changes in belief and attitude toward information technology usage: A theoretical model and longitudinal test. MIS Quarterly, 28(2), 229-254.

Bødker, M., Gimpel, G., \& Hedman, J. (2014). Time-out/time-in: The dynamics of everyday experiential computing devices. Information Systems Journal, 24(2), 143-166.

Breward, M., Hassanein, K., \& Head, M. (2017). Understanding consumers' attitudes toward controversial information technologies: A contextualization approach. Information Systems Research, 28(4), 760-774.

Brosnan, M. J. (2002). Technophobia: The psychological impact of information technology. London: Routledge.

Brown, S. R. (1980). Political subjectivity: Applications of Q methodology in political science. New Haven, CT: Yale University Press. Brown, S. R. (1993). A primer on Q methodology. Operant Subjectivity, 16(3/4), 91-138.

Bruner, J. S. (1990). Acts of meaning. Cambridge, MA: Harvard University Press. 
Bundele, M. M. \& Banerjee, R. (2009) Detection of fatigue of vehicular driver using skin conductance and oximetry pulse: A neural network approach. In: Proceedings of the 11th International Conference on Information Integration and Web-based Applications \& Services, Kuala Lumpur, Malaysia, 739-744.

Bygstad, B., Munkvold, B., \& Volkoff, O. (2016). Identifying generative mechanisms through affordances: A framework for critical realist data analysis. Journal of Information Technology, 31(1), 83-96.

Calvo, R. A. \& Peters, D. (2013) The irony and re-interpretation of our quantified self. In: Proceedings of the 25th Australian Computer-Human Interaction Conference: Augmentation, Application, Innovation, Collaboration, Adelaide, Australia, 367-370.

Canhoto, A. I., \& Arp, S. (2017). Exploring the factors that support adoption and sustained use of health and fitness wearables. Journal of Marketing Management, 33(1-2), 32-60.

Carlsson, M., \& Rooth, D.-O. (2007). Evidence of ethnic discrimination in the Swedish labor market using experimental data. Labour Economics, 14(4), 716-729.

Cazier, J. A., Jensen, A. S., \& Dave, D. S. (2008). The impact of consumer perceptions of information privacy and security risks on the adoption of residual RFID technologies. Communications of the Association for Information Systems, 23(1), 235-256.

Cheng, T., Migliaccio, G. C., Teizer, J., \& Gatti, U. C. (2013). Data fusion of real-time location sensing and physiological status monitoring for ergonomics analysis of construction workers. Journal of Computing in Civil Engineering, 27(3), 320-335.

Choi, B., Hwang, S., \& Lee, S. (2017). What drives construction workers' acceptance of wearable technologies in the work- place?: Indoor localization and wearable health devices for occupational safety and health. Automation in Construction, 84, 31-41.

Chung, C.-F. \& Danis, C. M. (2016) Integrating population-based patterns with personal routine to re-engage fitbit use. In: Proceedings of the 10th EAI International Conference on Pervasive Computing Technologies for Healthcare, Cancun, Mexico, 154-161.

Corr, S. (2001). An introduction to Q methodology, a research technique. The British Journal of Occupational Therapy, 64(6), 293-297. 
Cross, R. M. (2005). Exploring attitudes: The case for Q methodology. Health Education Research, 20(2), 206-213.

Davidson, E., \& Pai, D. (2004). Making sense of technological frames: Promise, progress, and potential. In B. Kaplan, D. P. Truex, D. Wastell, A. T. Wood-Harper, \& J. I. Degross (Eds.), Information systems research: Relevant theory and informed practice (pp. 473-491). New York: Kluwer Academic Publishers.

Davis, F. D. (1989). Perceived usefulness, perceived ease of use, and user acceptance of information technology. MIS Quarterly, 13(3), 319-339.

DeChurch, L. A., \& Mesmer-Magnus, J. R. (2010). Measuring shared team mental models: A meta-analysis. Group Dynamics: Theory, Research, and Practice, 14(1), 1-14.

Dennis, K. E. (1988). Q-methodology: New perspectives on estimating reliability and validity. In O. L. Strickland, \& C. F. Waltz (Eds.), Measurement of nursing outcomes (pp. 409-419). New York: Springer.

Dinev, T., \& Hart, P. (2006). An extended privacy calculus model for e-commerce transactions, Information Systems Research, 17(1), 61-80.

Donner, J. (2004). Microentrepreneurs and mobiles: An exploration of the uses of mobile phones by small business owners in Rwanda. Information Technologies and International Development, 2(1), 1-21.

Duus, R., Cooray, M., \& Page, N. (2017). Agentic technology: The impact of activity trackers on user behavior (an extended abstract). In M. Stieler (Ed.), Creating marketing magic and innovative future marketing trends (pp. 315-322). Cham: Springer.

Dvorak, J. L. (2008). Moving wearables into the mainstream: Taming the Borg. New York: Springer.

Dziopa, F., \& Ahern, K. (2011). A systematic literature review of the applications of Qtechnique and its methodology. Methodology, 7(2), 39-55.

Eden, C. (2004). Analyzing cognitive maps to help structure issues or problems. European Journal of Operational Research, 159(3), 673-686. 
Elbanna, A., \& Linderoth, H. C. (2015). The formation of technology mental models: The case of voluntary use of technology in organizational setting. Information Systems Frontiers, 17(1), 95-108.

Elie-Dit-Cosaque, C. M., \& Straub, D. W. (2011). Opening the black box of system usage: User adaptation to disruptive IT. European Journal of Information Systems, 20(5), 589-607.

Fadel, K. J., \& Brown, S. A. (2010). Information systems appraisal and coping: The role of user perceptions. Communications of the Association for Information Systems, 26(1), 107-126.

Faraj, S. \& Azad, B. (2012). The materiality of technology: An affordance perspective. In: Materiality and organizing: Social interaction in a technological world, Leonardi, P. M., Nardi, B. A. \& Kallinikos, J. (Eds.), pp. 237-258. Oxford University Press, Oxford.

Ferguson, E., Kerrin, M., \& Patterson, F. (1997). The use of multi-dimensional scaling (MDS): A cognitive mapping technique in occupational settings. Journal of Managerial Psychology, 12(3), 204-215.

Fingas, R. (2015). IBM adopts apple watch for internal fitness initiative \& Watson-linked health app [Online]. AppleInsider. Available: http://appleinsider.com/articles/15/10/27/ibm-adoptsapple-watch-for-internal-fitness-initiative-watson- linked-health-app [Accessed January 22, 2018].

Fox, S. (2013). The self-tracking data explosion. Washington, DC: Pew Research Center.

Gabriel, Y. (1999). Beyond happy families: A critical reevaluation of the control-resistanceidentity triangle. Human Relations, 52(2), 179-203.

Gao, Y., Li, H., \& Luo, Y. (2015). An empirical study of wearable technology acceptance in healthcare. Industrial Management \& Data Systems, 115(9), 1704-1723.

Ghobadi, S., \& Mathiassen, L. (2015). Perceived barriers to effective knowledge sharing in agile software teams. Information Systems Journal, 26(2), 95-125.

Gibson, J. J. (1979). The ecological approach to visual perception. Boston: Houghton Mifflin. Glance, D. G., Ooi, E., Berman, Y. e., Glance, C. F. \& Barrett, H. R. (2016) Impact of a digital activity tracker-based workplace activity program on health and wellbeing. In: Proceedings of the 6th International Conference on Digital Health Confer- ence, Montreal, Canada, 3741. 
Gorm, N. \& Shklovski, I. (2016). Steps, choices and moral accounting: Observations from a step-counting campaign in the workplace. In: Proceedings of the 19th ACM Conference on Computer-Supported Cooperative Work \& Social Comput- ing, San Francisco, USA, 148159.

Greenfield, R., Busink, E., Wong, C. P., Riboli-Sasco, E., Greenfield, G., Majeed, A., ... Wark, P. A. (2016). Truck drivers' perceptions on wearable devices and health promotion: A qualitative study. BMC Public Health, 16(1), 677.

Guo, L. (2015). Nudge better quantified-self with context-aware and proactive services. In: Proceedings of the 14th IEEE International Conference on Ubiquitous Computing and Communications, Liverpool, UK, 1527-1532.

Han, L., Zhang, Q., Chen, X., Zhan, Q., Yang, T., \& Zhao, Z. (2017). Detecting work-related stress with a wearable device. Computers in Industry, 90, 42-49.

Henfridsson, O., \& Lindgren, R. (2010). User involvement in developing mobile and temporarily interconnected systems. Information Systems Journal, 20(2), 119-135.

Hofmann, B. (2013). Ethical challenges with welfare technology: A review of the literature. Science and Engineering Ethics, 19(2), 389-406.

Iivari, J., \& Iivari, N. (2011). Varieties of user-centredness: An analysis of four systems development methods. Information Sys- tems Journal, 21(2), 125-153.

Iivari, J., Isomäki, H., \& Pekkola, S. (2010). The user-The great unknown of systems development: Reasons, forms, challenges, experiences and intellectual contributions of user involvement. Information Systems Journal, 20(2), 109-117.

Junglas, I., Goel, L., Abraham, C., \& Ives, B. (2013). The social component of information systems-How sociability contributes to technology acceptance. Journal of the Association for Information Systems, 14(10), 585-616.

Karahoca, A., Karahoca, D., \& Aksöz, M. (2017). Examining intention to adopt to internet of things in healthcare technology products. Kybernetes, 47(4) 742-770.

Klaus, T., Wingreen, S. C., \& Blanton, J. E. (2010). Resistant groups in enterprise system implementations: A Q-methodology examination. Journal of Information Technology, 25(1), $91-106$. 
Köffer, S. (2015). Designing the digital workplace of the future-What scholars recommend to practitioners. In: Proceedings of the 36th International Conference on Information Systems, Fort Worth, USA, 1-21.

Koo, S. H. (2017). Consumer differences in the United States and India on wearable trackers. Family and Consumer Sciences Research Journal, 46(1), 40-56.

Kordzadeh, N. (2014). Communicating personal health information in virtual health communities: An integration of privacy calculus model and affective commitment. San Antonio: The University of Texas.

Koskimäki, H., Huikari, V., Siirtola, P., Laurinen, P. \& Röning, J. (2009). Activity recognition using a wrist-worn inertial measurement unit: A case study for industrial assembly lines. In: Proceedings of the 17th Mediterranean Conference on Control and Automation, Thessaloniki, Greece, 401-405.

Lanamäki, A., Thapa, D., \& Stendal, K. (2016). When Is an Affordance? Outlining Four Stances. In L. Introna, D. Kavanagh, S. Kelly, W. Orlikowski \& S. Scott (Eds.), Beyond Interpretivism? New Encounters with Technology and Organization (pp. 125-139). Cham: Springer.

Lapointe, L., \& Rivard, S. (2005). A multilevel model of resistance to information technology implementation. MIS Quarterly, 29(3), 461-491.

Laukkanen, M., \& Eriksson, P. (2013). New designs and software for cognitive causal mapping. Qualitative Research in Organizations and Management: An International Journal, 8(2), 122147.

Lawrence, T. B., \& Robinson, S. L. (2007). Ain't misbehavin: Workplace deviance as organizational resistance. Journal of Management, 33(3), 378-394.

Lazarus, R. S., \& Folkman, S. (1984). Stress, appraisal, and coping. New York: Springer. Legris, P., Ingham, J., \& Collerette, P. (2003). Why do people use information technology? A critical review of the technology acceptance model. Information Management, 40(3), 191204.

Leonardi, P. M. (2011). When flexible routines meet flexible technologies: Affordance, constraint, and the imbrication of human and material agencies. MIS Quarterly, 35(1), 147167. 
Li, H., Wu, J., Gao, Y., \& Shi, Y. (2016). Examining individuals' adoption of healthcare wearable devices: An empirical study from privacy calculus perspective. International Journal of Medical Informatics, 88, 8-17.

Luik, J. (1999). Wardens, abbots, and modest hedonists: The problem of permission for pleasure in a democratic society. In S. Peele, \& M. Grant (Eds.), Alcohol and pleasure: A health perspective (pp. 25-35). Ann Arbor: Taylor \& Francis.

Majchrzak, A., \& Markus, M. L. (2012). Technology affordances and constraints in management information systems (MIS). In E. Kessler (Ed.), Encyclopedia of management theory. Thousand Oaks: Sage Publications.

Marakhimov, A., \& Joo, J. (2017). Consumer adaptation and infusion of wearable devices for healthcare. Computers in Human Behavior, 76, 135-148.

Markus, M. L., \& Silver, M. S. (2008). A foundation for the study of it effects: A new look at desanctis and poole's concepts of structural features and spirit. Journal of the Association for Information Systems, 9(10), 609-632.

McAfee, A., \& Brynjolfsson, E. (2012). Big data: The management revolution. Harvard Business Review, 90(10), 60-68.

McKeown, B., \& Thomas, D. B. (2013). Q methodology (2nd ed.). Thousand Oaks: Sage Publications.

Mettler, T. (2018). Contextualizing a professional social network for health care: Experiences from an action design research study. Information Systems Journal, 28, 684-707.

Mettler, T., Sprenger, M., \& Winter, R. (2017). Service robots in hospitals: New perspectives on niche evolution and technology affordances. European Journal of Information Systems, 26(5), 451-468.

Mukhopadhyay, T., Rajiv, S., \& Srinivasan, K. (1997). Information technology impact on process output and quality. Management Science, 43(12), 1645-1659.

Mura, M. D., Dini, G., \& Failli, F. (2016). An integrated environment based on augmented reality and sensing device for manual assembly workstations. Procedia CIRP, 41(Supplement C), 340-345.

Myers, M. D., \& Newman, M. (2007). The qualitative interview in IS research: Examining the craft. Information and Organization, 17(1), 2-26. 
Nambisan, S., Lyytinen, K., Majchrzak, A., \& Song, M. (2017). Digital innovation management: Reinventing innovation management research in a digital world. MIS Quarterly, 41(1), 223238.

Nevo, D., \& Wade, M. R. (2007). How to avoid disappointment by design. Communications of the ACM, 50(4), 43-48.

Norman, D. A. (1990). The design of everyday things. New York: Doubleday.

Norman, D. A. (2014). Some observations on mental models. In D. Gentner, \& A. L. Stevens (Eds.), Mental models (2nd ed.) (pp. 7-14). New York: Psychology Press.

Olsen, P. (2014). Wearable tech is plugging into health insurance [Online]. Forbes Magazine. Available: http://www.forbes. com/sites/parmyolson/2014/06/19/wearable-tech-healthinsurance/ [Accessed January 22, 2018].

Parasuraman, R., \& Manzey, D. H. (2010). Complacency and bias in human use of automation: An attentional integration. Human Factors: The Journal of the Human Factors and Ergonomics Society, 52(3), 381-410.

Peppoloni, L., Filippeschi, A., Ruffaldi, E., \& Avizzano, C. (2016). A novel wearable system for the online assessment of risk for biomechanical load in repetitive efforts. International Journal of Industrial Ergonomics, 52, 1-11.

Pina, L. R., Ramirez, E. \& Griswold, W. G. (2012) Fitbit+: A behavior-based intervention system to reduce sedentary behavior. In: Proceedings of the 6th International Conference on Pervasive Computing Technologies for Healthcare, San Diego, USA, 175-178.

Pozzi, G., Pigni, F. \& Vitari, C. (2014). Affordance theory in the IS discipline: A review and synthesis of the literature. In: Proceedings of the 20th Americas conference on information systems, Savannah, USA, 1-12.

Puri, A., Kim, B., Nguyen, O., Stolee, P., Tung, J., \& Lee, J. (2017). User acceptance of wristworn activity trackers among community-dwelling older adults: Mixed method study. JMIR mHealth and uHealth, 5(11), e173.

Ramlo, S. E., \& Newman, I. (2011). Q methodology and its position in the mixed methods continuum. Operant Subjectivity, 34(3), 172-191.

Rogers, E. M. (1962). Diffusion of innovations. New York: Free Press. 
Rouse, W. B., \& Morris, N. M. (1986). On looking into the black box: Prospects and limits in the search for mental models. Psychological Bulletin, 100(3), 349-363.

Schall, M. C. Jr., Sesek, R. F., \& Cavuoto, L. A. (2018, Forthcoming). Barriers to the adoption of wearable sensors in the work- place: A survey of occupational safety and health professionals. Human Factors, 60, 351-362.

Schwarz, A., \& Chin, W. (2007). Looking forward: Toward an understanding of the nature and definition of it acceptance. Journal of the Association for Information Systems, 8(4), 230243.

Seidel, S., Recker, J., \& vom Brocke, J. (2013). Sensemaking and sustainable practicing: Functional affordances of information systems in green transformations. MIS Quarterly, 37(4), 1275-1299.

Selander, L., \& Henfridsson, O. (2012). Cynicism as user resistance in it implementation. Information Systems Journal, 22(4), 289-312.

Shemmings, D. (2006). "Quantifying" qualitative data: An illustrative example of the use of Q methodology in psychosocial research. Qualitative Research in Psychology, 3(2), 147-165.

Shull, P. B., Jirattigalachote, W., Hunt, M. A., Cutkosky, M. R., \& Delp, S. L. (2014). Quantified self and human movement: A review on the clinical impact of wearable sensing and feedback for gait analysis and intervention. Gait \& Posture, 40(1), 11-19.

Silverman, R. E. (2013) Tracking sensors invade the workplace: Devices on workers, furniture offer clues for boosting productivity [Online]. New York. Available: http://www.wsj.com/articles/SB10001424127887324034804578344303 429080678 [Accessed January 22, 2018].

Stainton Rogers, R. (1995). Q methodology. In J. A. Smith, R. Harré, \& L. van Langenhove (Eds.), Rethinking methods in psychology (pp. 178-192). London: Sage Publications.

Starner, T. (2014). How wearables worked their way into the mainstream. IEEE Pervasive Computing, 13(4), 10-15.

Stenner, P. H., Cooper, D., \& Skevington, S. M. (2003). Putting the Q into quality of life; the identification of subjective constructions of health-related quality of life using Q methodology. Social Science \& Medicine, 57(11), 2161-2172. 
Stephenson, W. (1986). Protoconcursus: The concourse theory of communication: I. Operant Subjectivity, 9(2), 37-58.

Stephenson, W. (1993). Introduction to Q-methodology. Operant Subjectivity, 17(1), 1-13.

Storey, V. C., Straub, D. W., Stewart, K. A., \& Welke, R. J. (2000). A conceptual investigation of the e-commerce industry. Communications of the ACM, 43(7), 117-123.

Swan, M. (2013). The quantified self: Fundamental disruption in big data science and biological discovery. Big Data, 1(2), 85-99. Tan, F. B., \& Hunter, M. G. (2002). The repertory grid technique: A method for the study of cognition in information systems. MIS Quarterly, 26(1), 39-57.

Tashakkori, A., \& Teddlie, C. (2003). The past and future of mixed methods research: From data triangulation to mixed model designs. In A. Tashakkori, \& C. Teddlie (Eds.), Handbook of mixed methods in social \& behavioral research (pp. 671-702). Thousand Oaks: Sage Publications.

Thomas, D. M., \& Watson, R. T. (2002). Q-sorting and mis research: A primer. Communications of the Association for Information Systems, 8(1), 141-156.

Tractinsky, N., \& Jarvenpaa, S. L. (1995). Information systems design decisions in a global versus domestic context. MIS Quarterly, 19(4), 507-534.

Valenta, A. L., \& Wigger, U. (1997). Q-methodology: Definition and application in health care informatics. Journal of the American Medical Informatics Association, 4(6), 501-551.

Valero, E., Sivanathan, A., Bosché, F., \& Abdel-Wahab, M. (2016). Musculoskeletal disorders in construction: A review and a novel system for activity tracking with body area network. Applied Ergonomics, 54(Supplement C), 120-130.

Van Slyke, C., Shim, J., Johnson, R., \& Jiang, J. J. (2006). Concern for information privacy and online consumer purchasing. Journal of the Association for Information Systems, 7(1), 16.

Venkatesh, V., Morris, M. G., Davis, G. B., \& Davis, F. D. (2003). User acceptance of information technology: Toward a unified view. MIS Quarterly, 27(3), 425-478.

Vitharana, P., Zahedi, F., \& Jain, H. K. (2016). Enhancing analysts' mental models for improving requirements elicitation: A two- stage theoretical framework and empirical results. Journal of the Association for Information Systems, 17(12), 804-840. 
Volkoff, O., \& Strong, D. M. (2013). Critical realism and affordances: Theorizing it-associated organizational change processes. MIS Quarterly, 37(3), 819-834.

Vyas, D., Fitz-walter, Z., Mealy, E., Soro, A., Zhang, J. \& Brereton, M. (2015) Exploring physical activities in an employer-sponsored health program. In: Proceedings of the 33rd Annual ACM Conference Extended Abstracts on Human Factors in Computing Systems, Seoul, Republic of Korea, 1421-1426.

Warkentin, M., Goel, S., \& Menard, P. (2017). Shared benefits and information privacy: What determines smart meter technology adoption? Journal of the Association for Information Systems, 18(11), 758-786.

Watts, S., \& Stenner, P. (2012). Doing Q methodological research-Theory method and interpretation. London: Sage Publications. Wiegard, R.-B., \& Breitner, M. H. (2018, Forthcoming). Smart services in healthcare: A risk-benefit-analysis of pay-as-you-live services from customer perspective in Germany. Electronic Markets.

Wilson, H. J. (2013). Wearables in the workplace. Harvard Business Review, 91(11), 23-25.

Wolf, G. (2009) Know thyself: Tracking every facet of life, from sleep to mood to pain, 24/7/365 [Online]. Available: https:// www.wired.com/2009/06/lbnp-knowthyself/ [Accessed January 22, 2018].

Xu, H., Teo, H.-H., Tan, B. C., \& Agarwal, R. (2012). Research note-Effects of individual selfprotection, industry self-regulation, and government regulation on privacy concerns: A study of location-based services. Information Systems Research, 23(4), 1342-1363.

Yassaee, M., \& Mettler, T. (2017, Forthcoming). Digital occupational health systems: What do employees think about it? Information Systems Frontiers.

Zabala, A. (2014). Qmethod: A package to explore human perspectives using Q methodology. The R Journal, 6(2), 63-73. Zabala, A., \& Pascual, U. (2016). Bootstrapping Q methodology to improve the understanding of human perspectives. PLoS one, 11(2). e0148087 Zhang, M., Luo, M., Nie, R., \& Zhang, Y. (2017). Technical attributes, health attribute, consumer attributes and their roles in adoption intention of healthcare wearable technology. International Journal of Medical Informatics, 108, 97-109. 
Zhang, X., \& Chignell, M. (2001). Assessment of the effects of user characteristics on mental models of information retrieval

systems. Journal of the Association for Information Science and Technology, 52(6), 445-459. 


\section{Appendix - Detailed Q-methodology results}

Table A1. Experts involved in the concourse and q-sample phase.

\begin{tabular}{|c|c|}
\hline Type & Interviewees (duration of interview) \\
\hline Academic & $\begin{array}{l}\text { - } 1 \text { researcher in public health specialized in occupational medicine ( } 45 \mathrm{~min}) \\
\text { - } 1 \mathrm{x} \text { researcher in engineering specialized in human physiology ( } 55 \mathrm{~min}) \\
\text { - } 2 \mathrm{x} \text { researchers in public health specialized in e-health (each } 45 \mathrm{~min})\end{array}$ \\
\hline $\begin{array}{l}\text { Governmental or } \\
\text { parastatal agencies }\end{array}$ & $\begin{array}{l}\text { - } 2 \text { x representatives of the Swiss Federal Office for Health (each } 55 \mathrm{~min} \text { ) } \\
\text { - } 1 \text { x representative of a Swiss non-for-profit association for health promotion ( } 50 \\
\text { min) }\end{array}$ \\
\hline Private sector & $\begin{array}{l}\text { - } 1 \text { x manager at a physiolytics device manufacturing company ( } 65 \mathrm{~min} \text { ) } \\
\text { - } 2 \text { x software developers of nutrition and physical activity apps (each } 60 \mathrm{~min} \text { ) } \\
\text { - } 2 \text { x representatives of health insurances ( } 45 \mathrm{~min})\end{array}$ \\
\hline
\end{tabular}

Table A2. Study participants during the Q-sort ordered by factor loadings.

\begin{tabular}{|c|c|c|c|c|c|c|c|c|}
\hline ID & Employer & Age & Sex & $\mathrm{U}_{1}$ & $\mathbf{U}_{2}$ & $\mathrm{U}_{3}$ & $\mathrm{U}_{4}$ & $\mathrm{U}_{5}$ \\
\hline 12 & Public organization & 53 & $\mathrm{M}$ & $0.78^{\circ}$ & 0.07 & 0.18 & 0.04 & -0.15 \\
\hline 19 & Public organization & 33 & $\mathrm{~F}$ & $0.74^{\circ}$ & 0.17 & -0.06 & 0.09 & 0.31 \\
\hline 14 & Large corporation & 36 & M & $0.70^{\circ}$ & 0.40 & 0.12 & -0.13 & -0.06 \\
\hline 6 & Large corporation & 40 & $\mathrm{~F}$ & $0.69^{\circ}$ & $0.46^{*}$ & 0.21 & 0.12 & 0.02 \\
\hline 3 & Large corporation & 27 & $\mathrm{M}$ & $0.68^{\circ}$ & 0.28 & 0.02 & 0.30 & 0.09 \\
\hline 15 & Public organization & 63 & M & $0.62^{\circ}$ & -0.07 & 0.14 & 0.27 & 0.37 \\
\hline 10 & Large corporation & 24 & $\mathrm{~F}$ & $0.57^{\circ}$ & 0.03 & 0.25 & $0.52^{\circ}$ & 0.08 \\
\hline 7 & Large corporation & 24 & $\mathrm{~F}$ & 0.06 & 0.83 & 0.07 & 0.24 & -0.14 \\
\hline 17 & Public organization & 33 & $\mathrm{~F}$ & 0.34 & 0.79 & 0.14 & 0.02 & 0.09 \\
\hline 9 & Public organization & 53 & $\mathrm{~F}$ & 0.24 & $0.66^{*}$ & 0.18 & 0.10 & 0.36 \\
\hline 20 & Small and medium-sized company & 22 & $\mathrm{~F}$ & 0.29 & $0.60^{*}$ & $0.48^{*}$ & 0.26 & 0.08 \\
\hline 4 & Large corporation & 25 & $\mathrm{~F}$ & 0.15 & -0.05 & 0.89 & 0.11 & -0.01 \\
\hline 5 & Public organization & 60 & $\mathrm{~F}$ & 0.04 & 0.30 & $0.87^{*}$ & 0.09 & 0.00 \\
\hline 16 & Large corporation & 34 & M & 0.28 & 0.16 & 0.63 & 0.37 & 0.12 \\
\hline 2 & Large corporation & 30 & M & 0.25 & 0.13 & 0.19 & 0.82 & 0.04 \\
\hline 11 & Large corporation & 20 & $\mathrm{~F}$ & -0.15 & 0.32 & $0.46^{\circ}$ & $0.68^{*}$ & -0.14 \\
\hline 13 & Public organization & 47 & $\mathrm{~F}$ & 0.36 & 0.45 & -0.12 & $0.47^{*}$ & 0.00 \\
\hline 8 & Large corporation & 37 & $\mathrm{~F}$ & 0.17 & 0.00 & 0.08 & 0.29 & $0.81^{\circ}$ \\
\hline 1 & Small and medium-sized company & 25 & M & -0.04 & -0.05 & -0.22 & -0.27 & $0.79^{*}$ \\
\hline 18 & Large corporation & 24 & $\mathrm{~F}$ & 0.03 & 0.39 & 0.33 & -0.06 & 0.60 \\
\hline & Eigenvalues: & & & 7.26 & 2.40 & 1.81 & 1.62 & 1.20 \\
\hline & Percentage of variance explained: & & & $36.30 \%$ & $11.98 \%$ & $9.05 \%$ & $8.09 \%$ & $5.99 \%$ \\
\hline
\end{tabular}

Denote factor loadings that are significant, i.e. $\mathrm{SE}=1 / \mathrm{N}$, where $\mathrm{SE}$ is the standard error and $\mathrm{N}$ is the number of Qsort statements (S. R. Brown, 1993). For this study, the standard error comes out to $0.180(\mathrm{SE}=1 / 32)=1 / 5.657=$ 0.177). Correlations are considered to be statistically significant at the 0.01 level when they are in excess of 2.58 standard errors (irrespective of sign) or $2.58 \times(0.177)=0.456)$. 
Table A3. Consensus and distinguishing items

No Description

$\mathbf{U}_{1} \mathbf{U}_{2} \mathbf{U}_{3} \mathbf{U}_{4} \mathbf{U}_{5}$

14 I would only use algorithmic decision-making tools, if an independent organization watches over my personal information.

20 The use of such algorithmic decision-making tools within the scope of health prevention at work should be completely voluntary.

11 I would only use such an algorithmic decision-making tool, if I would get more leaves by the company.

31 Algorithmic decision-making tools for reducing health-related issues at work are positive new technological developments.

28 I would like to be monitored during all my job activities, knowing that it's done for the matter of my personal health.

22 All the data that is collected for the purpose of algorithmic decision-making needs to be completely anonymous.

24 It is hard for me to determine my health status accurately without the help of technology.

26 There should be no peer pressure when it comes to using algorithmic decision-making tools for health prevention at work

23 I don't know if I should applaud or deride companies that adopt algorithmic decision-making tools for improving their employees' health behavior.

30 When companies are interested in adopting algorithmic decision-making tools for reducing healthrelated issues at work, it means that they are genuinely concerned about the health of their employee

4 I don't fear to share my personal information with my employer for the purpose of performance appraisals.

10 I would only use such an algorithmic decision-making tool, if I would financially get recompensed by the company.

29 The use of such algorithmic decision-making tools within the scope of health prevention at work should also be fun.

17 I don't need a tool to tell me when I feel sick or stressed out.

6 When I feel stressed out, I communicate this directly to my manager.

5 I regularly disclose personal information on social networks.

12 I would like to use algorithmic decision-making tools, which support me to become healthier in my free time.

2 I fear that we will be monitored $24 / 7$ soon.

15 I believe that algorithmic decision-making tools afford employers more than to the employees.

19 The use of such algorithmic decision-making tools creates harm instead of improving the health status of an employee.

9 I fear that we will become totally dependent from such technologies.

13 Such technologies really help people to adopt healthier life choices.

27 Algorithmic decision-making tools for health prevention at work need to afford primarily benefits to employees.

8 Vocational trainings are more effective means to reduce the risk of stress-related absences than algorithmic decision-making tools.

18 I'm generally open to try algorithmic decision-making tools that help me to stay healthy at work.

32 I fear to become vulnerable when using algorithmic decision-making tools

16 I'm fully responsible for my health; the company should not worry about that.

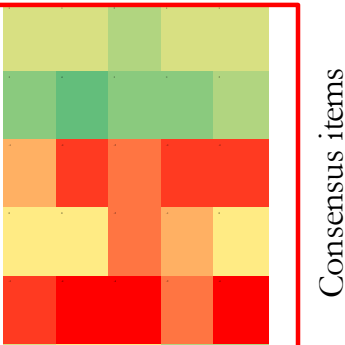

1 Assessments of employees (including health-related ones) should be performed by personal observations from managers and not by a surveillance system.

21 I fear that someone could abuse my personal information for other purposes.

3 Analyzing personal information is a way of the company to manipulate actions and opinions.

7 The best way to reduce stress-related absences is to prohibit the cash out of overtime and vacation days.

25 I believe that private matters (such as health) and business matters need to remain strictly separated.

Note: The original statements have been translated from German to English and simplified for clarity and easier interpretation. 
Table A4. Statements with highest and lowest agreement

28 I would like to be monitored during all my job activities, knowing that it's done for the matter of my personal health.

11 I would only use such an algorithmic decision-making tool, if I would get more leaves by the company.

10 I would only use such an algorithmic decision-making tool, if I would financially get recompensed by the company.

24 It is hard for me to determine my health status accurately without the help of technology.

$4 \quad$ I don't fear to share my personal information with my employer for the purpose of performance appraisals.

32 I fear to become vulnerable when using algorithmic decision-making tools.

30 When companies are interested in adopting algorithmic decision-making tools for reducing healthrelated issues at work, it means that they are genuinely concerned about the health of their employees.

5 I regularly disclose personal information on social networks.

31 Algorithmic decision-making tools for reducing health-related issues at work are positive new technological developments.

18 I'm generally open to try algorithmic decision-making tools that help me to stay healthy at work.

3 Analyzing personal information is a way of the company to manipulate actions and opinions.

23 I don't know if I should applaud or deride companies that adopt algorithmic decision-making tools for improving their employees' health behavior.

6 When I feel stressed out, I communicate this directly to my manager.

2 I fear that we will be monitored $24 / 7$ soon.

19 The use of such algorithmic decision-making tools creates harm instead of improving the health status of an employee.

8 Vocational trainings are more effective means to reduce the risk of stress-related absences than algorithmic decision-making tools.

21 I fear that someone could abuse my personal information for other purposes.

9 I fear that we will become totally dependent from such technologies.

29 The use of such algorithmic decision-making tools within the scope of health prevention at work should also be fun.

13 Such technologies really help people to adopt healthier life choices.

16 I'm fully responsible for my health; the company should not worry about that.

12 I would like to use algorithmic decision-making tools, which support me to become healthier in my free time.

15 I believe that algorithmic decision-making tools afford employers more than to the employees.

22 All the data that is collected for the purpose of algorithmic decision-making needs to be completely anonymous.

27 Algorithmic decision-making tools for health prevention at work need to afford primarily benefits to employees.

1 Assessments of employees (including health-related ones) should be performed by personal observations from managers and not by a surveillance system.

7 The best way to reduce stress-related absences is to prohibit the cash out of overtime and vacation days.

25 I believe that private matters (such as health) and business matters need to remain strictly separated.

14 I would only use algorithmic decision-making tools, if an independent organization watches over my personal information.

26 There should be no peer pressure when it comes to using algorithmic decision-making tools for health prevention at work.

17 I don't need a tool to tell me when I feel sick or stressed out.

20 The use of such algorithmic decision-making tools within the scope of health prevention at work should be completely voluntary.

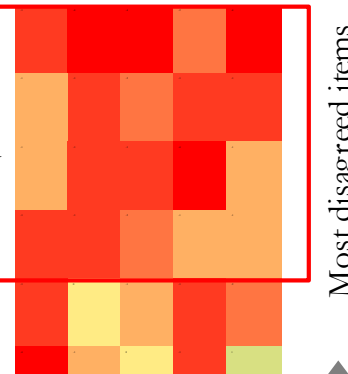

Note: The original statements have been translated from German to English and simplified for clarity and easier interpretation. 


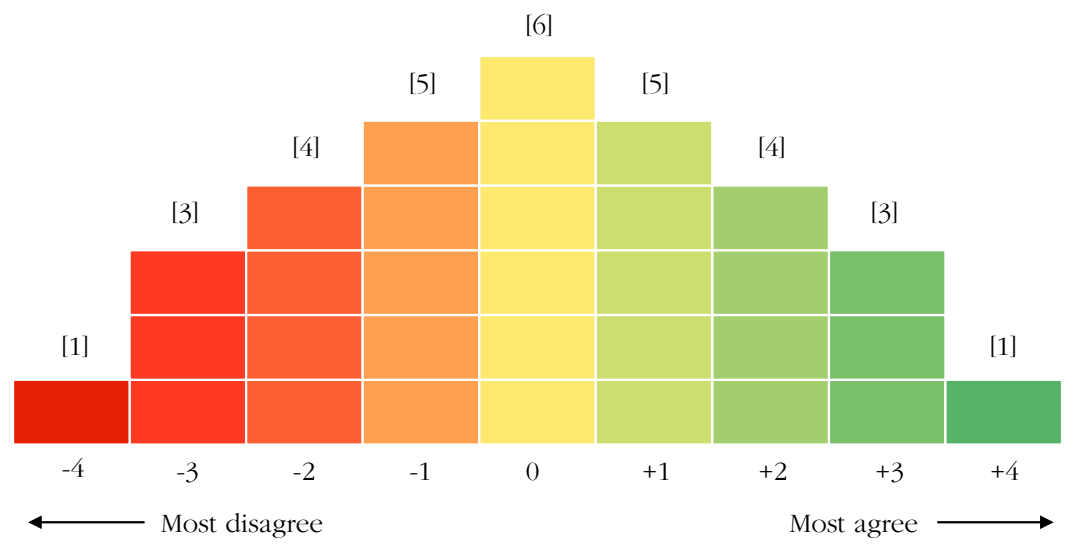

Figure A1. Fixed quasi-normal distribution used in this study; in brackets is the number of cards per ranking option 